\title{
Grãos detríticos de zircão do Grupo Itacolomi em sua área tipo, Quadrilátero Ferrífero, Minas Gerais: idades, proveniência e significado tectônico
}

\author{
Detrital zircons of the Itacolomi Group in its type area, Quadrilátero \\ Ferrifero, Minas Gerais, Brazil: ages, provenance and tectonic significance
}

\author{
Tiago Rocha Faria Duque ${ }^{1}$ (D), Fernando Flecha de Alkmim¹ (D), Cristiano de Carvalho Lana ${ }^{1}$ (iD \\ ${ }^{1}$ Universidade Federal de Ouro Preto - UFOP, Departamento de Geologia, Escola de Minas, Departamento de \\ Engenharia Geológica - DEGEO, Campus Morro do Cruzeiro s/n, Bauxita, CEP 35.400-000, Ouro Preto, MG, BR \\ (tiagorfduque@gmail.com; ffalkmim@gmail.com; cristianodeclana@gmail.com)
}

Recebido em 29 de outubro de 2018; aceito em 6 de fevereiro de 2020

\begin{abstract}
Resumo
O Grupo Itacolomi em sua localidade tipo, a serra homônima, situada na porção sudeste do Quadrilátero Ferrífero, Minas Gerais, caracteriza-se por uma sucessão de meta-arenitos, metaconglomerados e filitos. Nessa e demais ocorrências, o grupo é interpretado como uma associação de depósitos fluviais e de leques aluviais, acumulados em bacias intermontanas pós-orogênicas. As suas ocorrências na localidade tipo dão-se na forma de um bloco basal autóctone que jaz em discordância sobre rochas do Supergrupo Minas, e outro superior alóctone, lançado sobre o primeiro por uma falha de empurrão. O bloco autóctone corresponde à porção íntegra e internamente menos deformada do grupo e é constituído de um pacote de aproximadamente $400 \mathrm{~m}$ de meta-arenitos e metaconglomerados. No bloco alóctone, exposto no Pico do Itacolomi, meta-arenitos finos a médios com espessura de aproximadamente $145 \mathrm{~m}$ encontram-se, em geral, mais intensamente deformados. Os espectros de idades dos grãos de detríticos de zircão obtidos nos blocos autóctone e alóctone são ligeiramente diferentes. Os do primeiro são claramente unimodais, com picos em 2167, 2197 e 2203 Ma. Os do segundo são bimodais, com picos principais em 2156 e $2201 \mathrm{Ma}$. Eles indicam que as fontes principais do grupo devem ter sido, principalmente, os granitoides paleoproterozoicos do Cinturão Mineiro e do Complexo Mantiqueira, expostos respectivamente a sudoeste e leste da Serra do Itacolomi. A idade máxima de sedimentação do grupo pode ser estimada em $2129 \pm 11$ Ma. Esses resultados, juntamente com outros disponíveis na literatura, indicam que o Grupo Itacolomi foi depositado em bacia de antepaís do orógeno paleoproterozoico que abarca o Quadrilátero Ferrífero e áreas adjacentes.
\end{abstract}

Palavras-chave: Grupo Itacolomi; Paleoproterozoico; Quadrilátero Ferrífero; Zircão detrítico, Proveniência.

\begin{abstract}
The Itacolomi Group in its type area, the homonymous ridge located in the southeastern portion of Quadrilátero Ferrífero mineral province in State Minas Gerais, is made up of a succession of metasandstones, metaconglomerates and phyllites, interpreted as fluvial to alluvial fan deposits accumulated in post-orogenic intermontane basins. In the type locality, the group is exposed in the form of a basal autochthonous package that unconformably overlies the 2.6-2.1 Ga Minas Supergroup, and an allochthonous block bounded by thrust faults. The c. $400 \mathrm{~m}$-thick autochthonous succession is weakly deformed and composed of metasandstones and metaconglomerates. Exposed in the Itacolomi Peak, the 145 m-thick finegrained metasandstones of the thrust sheet are intensively deformed. The detrital zircon age spectra obtained from these packages are slightly different. The spectra of the basal autochthonous package are clearly unimodal with age peaks at 2167, 2197 and $2203 \mathrm{Ma}$, whereas the age distributions of the upper thrust sheet are bimodal with peaks at 2156 and 2201 Ma. They indicated that the group was sourced essentially by the Paleoproterozoic arc-related granitoids of the Mineiro belt and Mantiqueira Complex, exposed respectively to the southwest and east of the Itacolomi ridge. The maximum deposition age of the group can be estimated at $2129 \pm 11 \mathrm{Ma}$. These results confirm the post-orogenic nature of the Itacolomi succession, which accumulated in a back-arc/foreland setting in respect to the Paleoproterozoic orogen exposed in the Quadrilátero Ferrífero and adjacent areas.
\end{abstract}

Keywords: Itacolomi Group; Paleoproterozoic; Quadrilátero Ferrífero; Detrital Zircon, Provenance. 


\section{INTRODUÇÃO}

O conjunto de rochas metassedimentares que aflora na Serra e no Pico do Itacolomi nos municípios de Ouro Preto e Mariana, em Minas Gerais, foi primeiramente descrito em mais detalhes por Harder e Chamberlin (1915). Após a campanha de cartografia geológica de detalhe do Quadrilátero Ferrífero $(\mathrm{QF})$, cujos resultados encontram-se sintetizados em Dorr (1969), a sucessão de meta-arenitos e metaconglomerados aflorante na região em foco foi individualizada como "Série" Itacolomi, e a serra e pico homônimos tornaram-se sua localidade tipo. Para os autores participantes da campanha, Barbosa (1959) e Dorr (1969), o Grupo Itacolomi corresponderia à unidade mais jovem da sequência pré-cambriana do QF e representaria sedimentos pós-orogênicos, depositados em bacias intermontanas terminais ("fácies molassa") da evolução do "geossinclinal" Minas.

Mesmo tendo sido objeto de alguns estudos de natureza tectônica, estratigráfica e sedimentológica (Glöckner, 1981; Tessari Filho e Amorim, 1984; Ferreira e Lazarin, 1993) e, mais recentemente, geocronológica (Machado et al., 1996; Hartmann et al., 2006), muitas questões ainda permanecem em aberto sobre o Grupo Itacolomi na sua área tipo. Entre elas, destacam-se:

- a natureza parcial ou totalmente alóctone do grupo;

- a proveniência e a idade da sucessão, uma vez que os dados geocronológicos até agora disponíveis foram obtidos em número relativamente pequeno de grãos detríticos de zircão;

- a hipótese ainda não devidamente testada de Barbosa (1959) e Dorr (1969) sobre o significado da unidade na evolução tectônica do QF.

No presente artigo, apresentam-se os resultados de uma investigação geocronológica do Grupo Itacolomi em sua área tipo, o qual se fundamenta na determinação de idades de grãos detríticos de zircão pelo método U-Pb LA-ICPMS (Laser Ablation Inductively Coupled Plasma Mass Spectrometry). Essa investigação foi precedida por cartografia geológica de detalhe e de estudos estratigráficos, sedimentológicos e estruturais que visaram oferecer respostas às questões em aberto anteriormente mencionadas. Com este trabalho, pretendeu-se contribuir para um melhor entendimento da evolução tectônica paleoproterozoica do QF e, por conseguinte, da porção sul do Cráton do São Francisco, bem como do significado tectônico de sucessões de arenitos e conglomerados acumuladas em cenários similares.

\section{O GRUPO ITACOLOMI NO QUADRILÁTERO FERÍFERO}

$\mathrm{O} Q \mathrm{QF}$ ocupa uma área de aproximadamente $7.000 \mathrm{~km}^{2}$ no centro de Minas Gerais, que é caracterizado por relevo anomalamente pronunciado face à sua pertinência ao Escudo Atlântico. De acordo com a literatura atual, o QF e adjacências fazem parte de dois componentes geotectônicos do Escudo Atlântico: o Cráton São Francisco e a Faixa Araçuaí (Brasiliana) que o limita pelo Leste (Figura 1). Nessa região, as principais unidades litoestratigráficas presentes são:

- Complexos metamórficos de idade arqueana, compostos de gnaisses TTG, migmatitos e granitoides de idades compreendidas entre 3,20 e 2,68 Ga (Machado et al., 1992, 1996; Machado e Carneiro, 1992; Teixeira et al., 1996; Noce et al., 2005; Lana et al., 2013; Romano et al., 2013), cuja maior parte constitui o embasamento para as demais assembleias da região;

- O Supergrupo Rio das Velhas, uma típica sucessão greenstone belt, composta de rochas metavulcânicas e metassedimentares de idades arqueanas compreendidas entre 3450 e $2700 \mathrm{Ma}$ (Machado et al., 1996; Hartmann et al., 2006; Baltazar e Zuchetti, 2007; Farina et al., 2016) (Figuras 2 e 3);

- O Supergrupo Minas, que engloba uma assembleia de margem passiva (grupos Tamanduá, Caraça, Itabira e Piracicaba) a sin-orogência (Grupo Sabará) (Figuras 2 e 3), depositada entre 2,6 e 2,1 Ga (Machado et al., 1996; Brueckner et al., 2000; Martínez-Dopico et al., 2017);

- Uma assembleia de granitoides e sucessões vulcanossedimentares de idades compreendidas entre 2,47 e 2,10 Ga que constituem o chamado Cinturão Mineiro (Seixas et al., 2012; Seixas et al., 2013; Ávila et al., 2014; Barbosa et al., 2015; Teixeira et al., 2015);

- Uma associação entre rochas gnáissicas arqueanas e plútons paleoproterozoicos (3,2 a 2,0 Ga) agrupados sob a denominação de Complexo Mantiqueira (Noce et al., 2007);

- O Grupo Itacolomi, objeto do presente estudo, constituído de meta-arenitos e metaconglomerados.

- Diques máficos que cortam todas as unidades (Silva et al., 1995; Girardi et al., 2017).

A definição do Grupo Itacolomi se estabelece definitivamente a partir da confecção da coluna estratigráfica para QF por Dorr (1969), que foi antecedida pelos dados produzidos sobre o "Quartzito Itacolomi" por vários autores (por exemplo, Harder e Chamberlin, 1915; Guimarães, 1931; Lacourt, 1935; Barbosa, 1949; Guild, 1957; Barbosa, 1959) (Tabela 1).

Dorr (1969) caracteriza a "Série Itacolomi" como a unidade pré-cambriana mais jovem do QF que estaria assentada em discordância angular sobre todas as demais expostas na região e conteria duas fácies distintas: a Itacolomi e a Santo Antônio. A primeira englobaria os quartzitos e os metaconglomerados que predominam nas exposições à unidade. A segunda seria caracterizada por rochas essencialmente ricas em hematita, incluindo meta-arenitos hematíticos, conglomerados e brechas ricos em clastos de formações ferríferas. Para esse autor, e também segundo Barbosa 


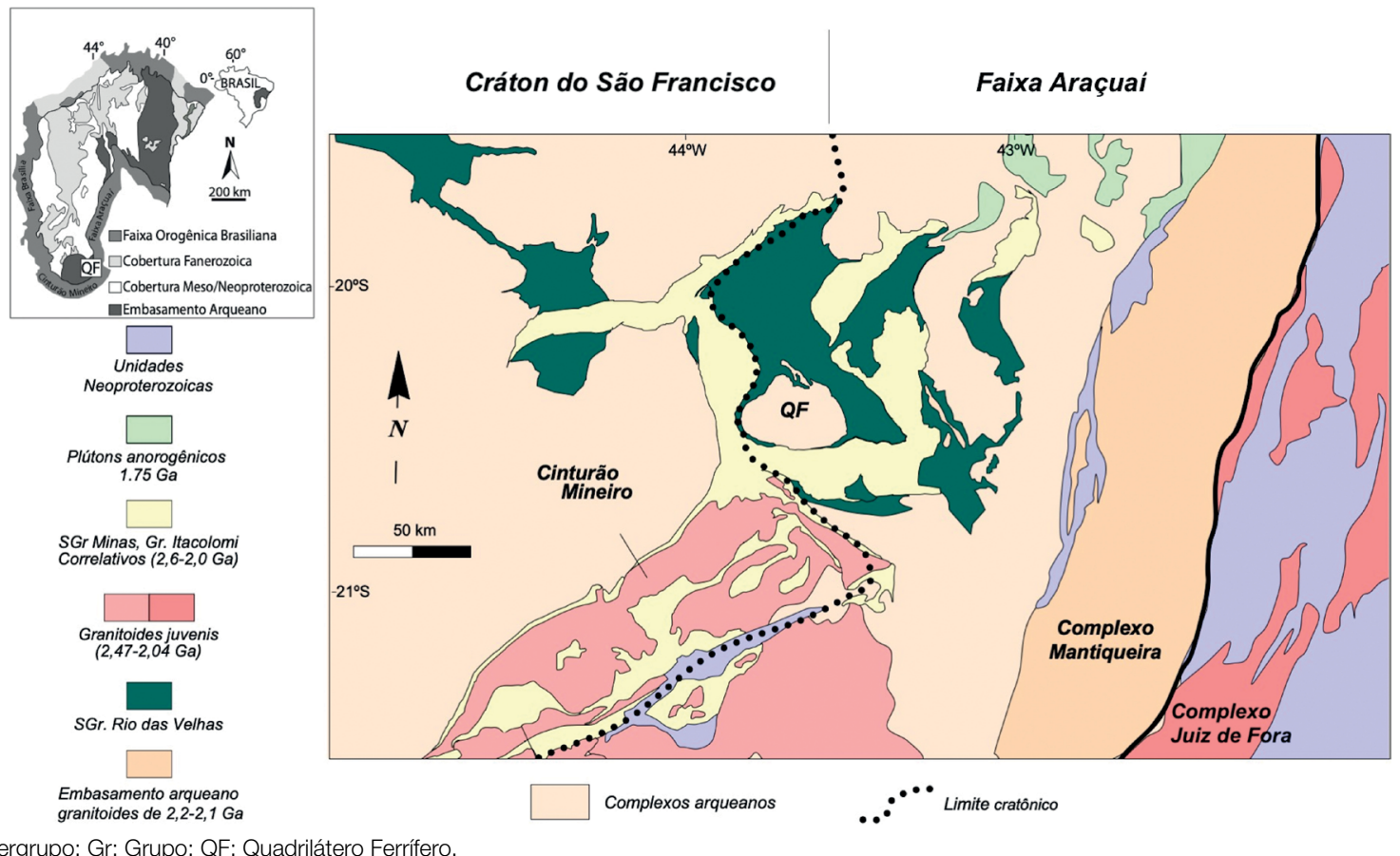

SGr: Supergrupo; Gr: Grupo; QF: Quadrilátero Ferrífero.

Fonte: modificado de Farina et al. (2016) e Alkmim e Teixeira (2017).

Figura 1. Mapa geológico simplificado da região do Quadrilátero Ferrífero e adjacências, que compreende o extremo sudeste do Cráton do São Francisco e parte da Faixa Araçuaí. Nele são destacadas as grandes unidades litoestratigráficas expostas na região.

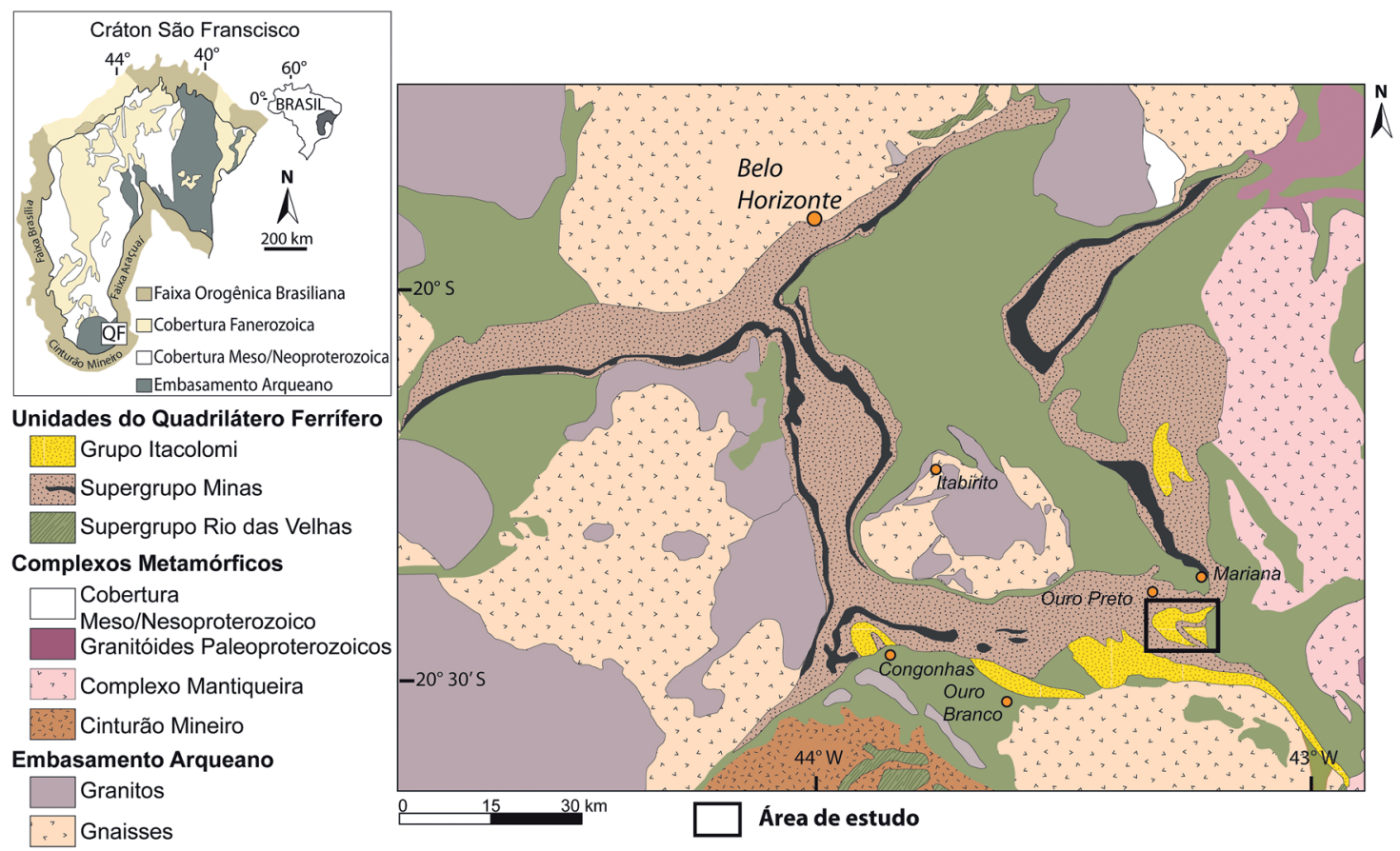

QF: Quadrilátero Ferrífero.

Fonte: adaptado de Alkmim e Marshak (1998) e Farina et al. (2016).

Figura 2. Mapa geológico simplificado da região do Quadrilátero Ferrífero com a distribuição das unidades estratigráficas maiores e, especialemente, do Grupo Itacolomi. A caixa em preto destaca a área tipo do Grupo Itacolomi, objeto do presente estudo. 
(1959) que lhe antecedeu, a "Série" Itacolomi marcaria os estágios finais da evolução geotectônica da região, representando a deposição molássica em bacias intermontanas.

No mapa geológico da Folha Mariana, 1:25.000, Barbosa (1969) distingue, na área tipo, duas ocorrências do Grupo Itacolomi: uma autóctone, exposta na base e no platô da serra em discordância sobre o Supergrupo Minas, e outra alóctone, aflorante no pico do Itacolomi e lançada, juntamente com um pacote de filitos do Grupo Sabará (Supergrupo Minas), sobre a primeira por uma falha de empurrão.

Glöckner (1981), em estudo estratigráfico e tectônico, cartografou, em escala 1:10.000, as ocorrências da unidade

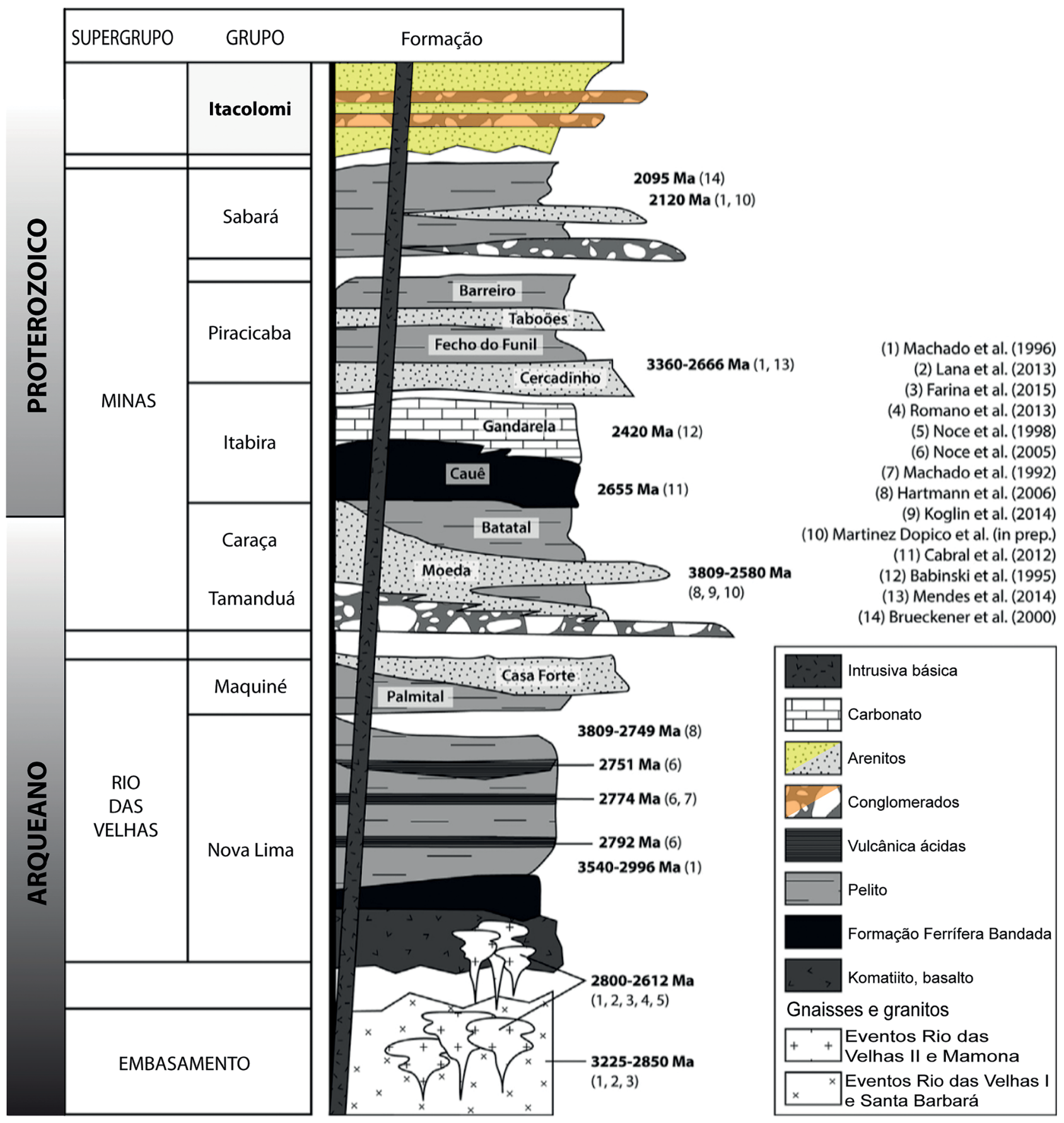

Fonte: adaptado de Farina et al. (2016).

Figura 3. Coluna estratigráfica da região do Quadrilátero Ferrífero com as respectivas idades e destaque para 0 Grupo Itacolomi. 
sul de Ouro Preto. Para ele, todas as ocorrências do grupo teriam caráter alóctone, de modo que a sua posição estratigráfica seria incerta. Além disso, tomando por base o conteúdo em minerais pesados, concluiu que os meta-arenitos do Pico do Itacolomi não pertenceriam ao grupo e deveriam ser correlacionados às unidades pré-Minas.

Tessari Filho e Amorim (1984) realizam um estudo sedimentológico e estrutural em uma porção do grupo exposta na face norte da Serra do Itacolomi, que corresponde à zona de ocorrência da fácies Santo Antônio, e postulam que se trata de depósitos de leques aluviais e alimentados essencialmente por rochas ferríferas.

Machado et al. (1996) determinaram idades de grãos detríticos de zircão em várias amostras do grupo, sendo duas delas coletadas na área tipo. Dada a presença marcante de idades entre $2,2 \mathrm{e} 2,0 \mathrm{Ga}$, os autores postulam que as fontes do grupo seriam rochas geradas durante a orogênese Transamazônica. Com base na idade obtida em um grão, estimam a idade máxima de sedimentação da unidade em $2059 \pm 58$ Ma.
Hartmann et al. (2006) realizaram a determinação pelo método U-Pb SHIRIMP II da idade de seis grãos de zircão extraídos de uma amostra do grupo coletada na sua área tipo. Obtêm, em um grão, a idade mais jovem de $2143 \pm 16 \mathrm{Ma}$. Por correlações regionais sugerem que a deposição da unidade teria se dado posteriormente à orogênese Transamazônica, porém com idades mais novas que 2,03 Ga.

De acordo com o conhecimento atual, as ocorrências do Grupo Itacolomi concentram-se no extremo sul do QF, onde assenta principalmente sobre rochas do Supergrupo Minas (Figura 2). Em algumas localidades, recobre rochas do Supergrupo Rio das Velhas e dos complexos metamórficos do embasamento. Nestas, os contatos são, na maioria dos casos, marcados por zonas de cisalhamento (Guild, 1957; Barbosa, 1959, 1968; Wallace, 1965; Dorr, 1969; Maxwell, 1972; Alkmim, 1987). Em todas elas, os litotipos dominantes são quartzo meta-arenitos; em menor proporção, tem-se metaconglomerados e, apenas subordinadamente, metapelitos.

Tabela 1. Síntese da evolução do conhecimento sobre o Grupo Itacolomi.

\begin{tabular}{|c|c|c|}
\hline Autor & Ano & \\
\hline Eschwege & 1811 & Denominou de itacolomitos as rochas da Serra do Itacolomi. \\
\hline Pissis & 1848 & $\begin{array}{l}\text { Executou um perfil de aproximadamente } 12 \text { km iniciado de sul para norte do Pico Itacolomi até a } \\
\text { Serra de Antônio Pereira, caracterizando o anticlinal de Mariana (Machado et al., 2010). }\end{array}$ \\
\hline Gorceix & 1883 & $\begin{array}{l}\text { Separou os quartzitos da região de Ouro Preto em dois níveis: o basal e o superior (atualmente os } \\
\text { quartzitos Moeda e Itacolomi, respectivamente). }\end{array}$ \\
\hline Derby & 1906 & Concluiu que os quartzitos Itacolomi representam o nível superior da coluna estratigráfica da região. \\
\hline $\begin{array}{l}\text { Harder e } \\
\text { Chamberlin }\end{array}$ & 1915 & $\begin{array}{l}\text { Concluíram que há uma separação na sequência das rochas quartzíticas da Serra do Itacolomi feita } \\
\text { por rochas pelíticas. }\end{array}$ \\
\hline Guimarães & 1931 & Reconheceu a discordância na base da unidade. \\
\hline Lacourt & 1935 & $\begin{array}{l}\text { Apresentou mapa da Folha de Ouro Preto, com descrições petrográficas detalhadas dos quartzitos } \\
\text { e estima a espessura da unidade em } 400 \text { m. }\end{array}$ \\
\hline Guild & 1957 & $\begin{array}{l}\text { Correlacionou as rochas ferruginosas da Formação Santo Antônio descritas por Barbosa (1949), na } \\
\text { região de Congonhas ao Grupo Itacolomi, caracterizando-a como uma fácies da unidade. }\end{array}$ \\
\hline Dorr & 1969 & $\begin{array}{l}\text { Definiu a "Série Itacolomi" constituída de duas fácies: quartzitos, "tipo Itacolomi”, e quartzitos com } \\
\text { filitos, metaconglomerados e meta-brechas ricas em hematita como fácies Santo Antônio. }\end{array}$ \\
\hline Glöckner & 1981 & $\begin{array}{l}\text { Posicionou as rochas do Pico Itacolomi e o xisto em sua base como pertencentes a unidades } \\
\text { pré-Minas. Subdividiu o Grupo Itacolomi s.s. em três unidades com base no seu conteúdo de } \\
\text { minerais pesados. }\end{array}$ \\
\hline Alkmim & 1987 & $\begin{array}{l}\text { Descreveu unidades de litofácies características de leques aluviais e sistema fluvial entrelaçado com } \\
\text { transição para uma planície de maré, na ocorrência da unidade na Serra de Ouro Branco. }\end{array}$ \\
\hline $\begin{array}{l}\text { Tessari Filho } \\
\text { e Amorim }\end{array}$ & 1984 & $\begin{array}{l}\text { Interpretaram as rochas do grupo na região de Passagem de Mariana como molassas e que teriam } \\
\text { participado de evento deformacional principal que afeta o Supergrupo Minas na região. }\end{array}$ \\
\hline $\begin{array}{l}\text { Machado } \\
\text { et al. }\end{array}$ & 1996 & $\begin{array}{l}\text { Primeiras datações de grãos de zircão do Grupo Itacolomi e estimativa de idade máxima de } \\
\text { sedimentação em } 2059 \pm 58 \text { Ma. Para esses autores, as principais populações de grãos de zircão } \\
\text { seriam derivadas de fontes geradas durante a orogênese Transamazônica. }\end{array}$ \\
\hline $\begin{array}{l}\text { Almeida } \\
\text { et al. }\end{array}$ & 2005 & $\begin{array}{l}\text { A partir de estudos realizados a sul de Ouro Preto, propõem a incorporação dos meta-arenitos } \\
\text { ali aflorantes (cartografados por Barbosa, } 1969 \text { como Gr. Itacolomi) ao Grupo do Sabará, sob a } \\
\text { denominação Formação Estrada Real. }\end{array}$ \\
\hline $\begin{array}{l}\text { Hartmann } \\
\text { et al. }\end{array}$ & 2006 & $\begin{array}{l}\text { Novas datações pelo método U-Pb-SHIRIMP II levaram os autores a postular a deposição do grupo } \\
\text { após } 2030 \text { Ma. }\end{array}$ \\
\hline
\end{tabular}




\section{O GRUPO ITACOLOMI EM SUA ÁREA TIPO}

A área tipo do grupo, que compreende a Serra e o Pico do Itacolomi, fica situada entre os municípios de Ouro Preto e Mariana, na região de abrangência do Parque Estadual do Itacolomi (Figura 4).

Distinguem-se, na área, duas ocorrências do grupo. A primeira ocupa o sopé e o platô da serra, e se estende na direção leste-oeste desde a região de Passagem de Mariana, passando pelos bairros a sul de Ouro Preto até o Morro do Cachorro, e dali para sul até a Fazenda do Manso (sede do Parque Estadual do Itacolomi). Dessa localidade, segue com direção WNW até a Fazenda do Cibrão, e termina próximo ao rio Gualaxo do Sul (Figura 4). Essa ocorrência é caracterizada por uma sucessão de meta-arenitos e metaconglomerados com aproximadamente $400 \mathrm{~m}$ de espessura máxima. Como afirmaram Guimarães (1931), Barbosa $(1959,1968)$ e Dorr (1969), essas rochas assentam discordantemente sobre as rochas do Supergrupo Minas, especificamente sobre os grupos Piracicaba (localmente) e Sabará (Figura 4). A segunda ocorrência é a do Pico do Itacolomi e da área imediatamente a leste. Nela, tem-se um pacote de meta-arenitos de $145 \mathrm{~m}$ de espessura, que na base e no topo se apresenta intensamente deformado. Nessas porções, faz contato (cisalhado) com filitos e xistos granatíferos do Grupo Sabará e por falha de empurrão com xistos do Supergrupo Rio das Velhas, que o recobrem a leste (Figura 4).

Em função da natureza das exposições e da intensidade da deformação, o levantamento estratigráfico e sedimentológico em que se baseia este estudo (Duque, 2018) só pôde ser levado a efeito na sucessão inferior e autóctone do grupo. As descrições relativas a esses aspectos apresentadas a seguir referem-se, portanto, somente a essa sucessão. Por outro lado, como indicado adiante, a amostragem para extração de grãos de zircão foi realizada em ambas as ocorrências.

\section{Estratigrafia}

Perfis estratigráficos de detalhe levantados em várias partes do bloco autóctone (Figura 5) revelaram sucessões de

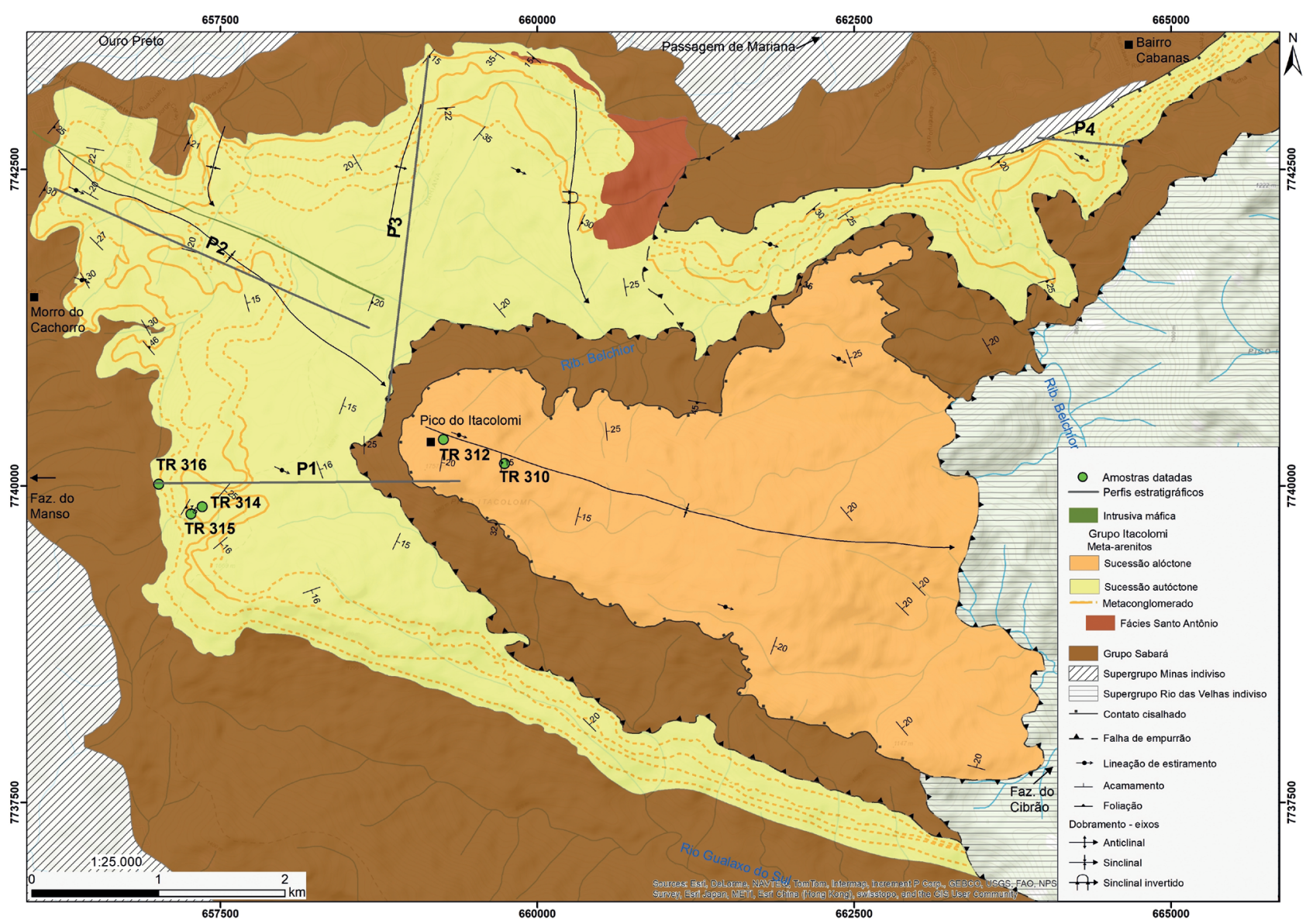

Figura 4. Mapa geológico da área tipo do Grupo Itacolomi (confeccionado com base em Dorr, 1969; e Glöckner, 1981), mostrando a distribuição das sucessões autóctone e alóctone. Indica-se também a localização dos perfis estratigráficos levantados e dos pontos de coleta de amostras para geocronologia. 
centenas de metros de meta-arenitos e metaconglomerados de origem fluvial que mostram afinamento granulométrico para o topo. Essas são compostas de ciclos de hierarquia inferior organizados da mesma forma. Nelas, predominam francamente os meta-arenitos com estratificação cruzada acanalada, nos quais se intercalam arenitos com estratificação cruzada tabular planar, meta-arenitos com estratificação plano-paralela, metaconglomerados finos com estratificação cruzada acanalada e metaconglomerados grosseiramente estratificados com gradação normal. Nos meta-arenitos são frequentes as lentículas e as lâminas de metapelitos. Essa sucessão, como sugerido por Glöckner (1981), pode ser subdivida em três unidades:

i) Basal, constituída de areia média a grossa com estratificações cruzadas acanaladas e com vários leitos e lentes de conglomerados polimíticos/monomíticos de granulação muito grossa. Está nela incluída a Fácies Santo Antônio, cujas características principais são granulação grossa e caráter ferruginoso. Essa unidade possui aproximadamente $135 \mathrm{~m}$ de espessura máxima e contém vários corpos de conglomerados ricos em clastos de formação ferrífera;

ii) Intermediária, formada por areia média a grossa e conglomerados relativamente mais finos, com cerca de $145 \mathrm{~m}$ de espessura máxima;

iii) Superior, composta de areia fina a média com estratificação cruzada acanalada e tabular planar. Possui espessura máxima de aproximadamente $130 \mathrm{~m}$ e situa-se acima do conglomerado M4 (Figura 5).

Os meta-arenitos são quartzosos e micáceos, com minerais pesados marcando a estratificação. São compostos de quartzo (75-90\%), moscovita (10-15\%), sericita (3-5\%), feldspatos (3-5\%), opacos (2-5\%) e zircão (1\%). Em algumas amostras, ocorrem também clorita (3\%) e turmalina (1\%). A textura é inequigranular, caracterizada por uma matriz de grãos de quartzo com contatos poligonais, sericita e raros cristais de feldspato, na qual se distribuem porfiroclastos de quartzo, parcial ou totalmente recristalizados. A trama da rocha é lepidoblástica, com moscovita, grãos individuais e

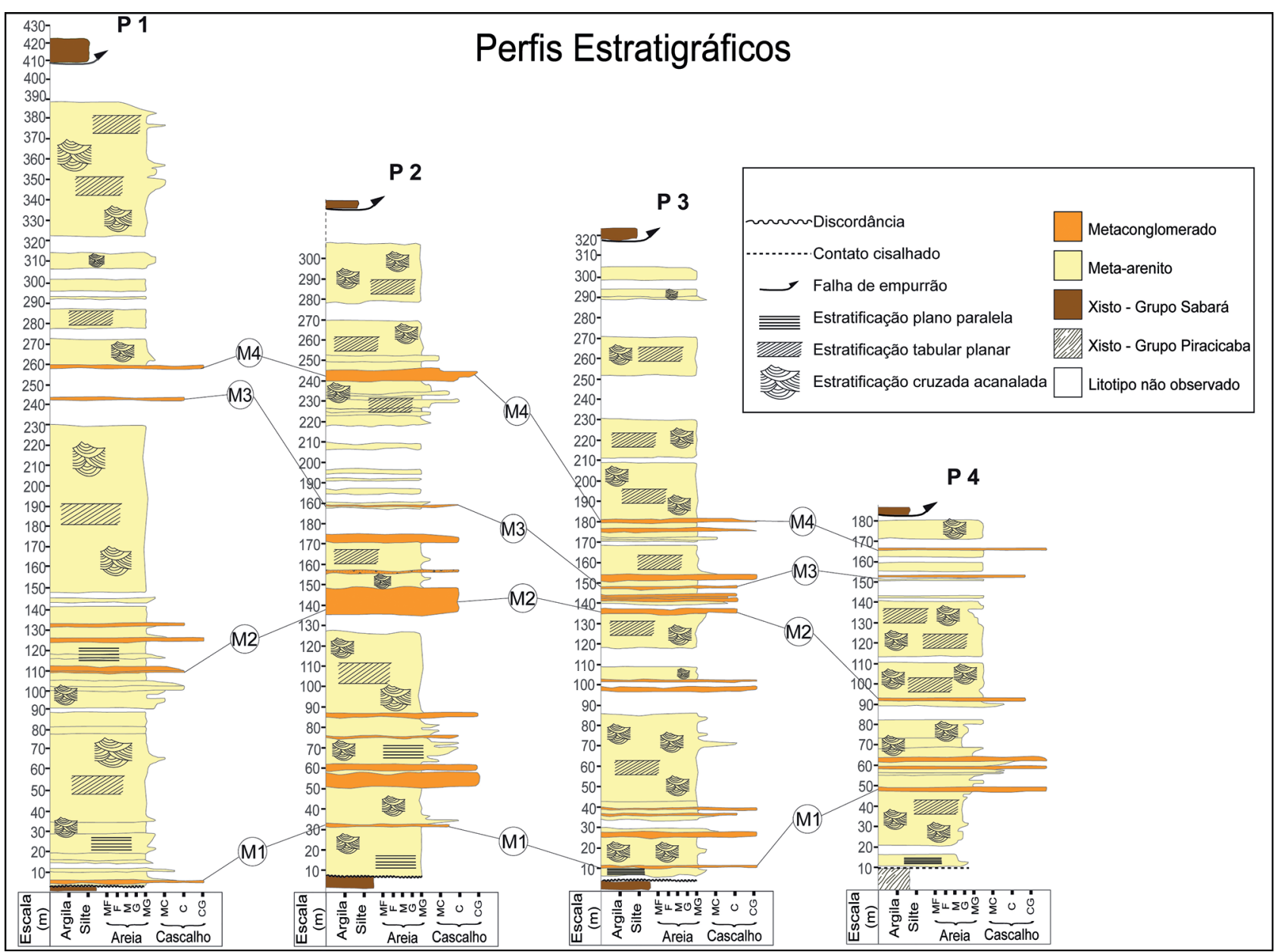

Figura 5. Perfis estratigráficos da sucessão do Grupo Itacolomi no bloco autóctone da área tipo. 
agregados de quartzo definindo a foliação. Os opacos são magnetita e, subordinadamente, hematita.

Os metaconglomerados possuem clastos de quartzo de veio, quartzito, quartzito ferruginoso, formação ferrífera bandada, filito e, em apenas um deles, fragmentos de turmalinito. Na maioria das camadas, predominam clastos de quartzo de veio e quartzito com tamanho médio variando entre 2 e $7 \mathrm{~cm}$. Localmente, foram observados clastos de até $20 \mathrm{~cm}$. A matriz arenosa exibe as mesmas características anteriormente descritas.

Os metapelitos se apresentam como sericita filitos de coloração esverdeada e ocorrem na forma de finas lâminas e lentículas de até $5 \mathrm{~cm}$ de espessura, intercaladas aos meta-arenitos. De modo geral, apresentam-se intensamente foliados em contraste com as rochas nas quais se inserem.

\section{Estrutura}

Em sua área tipo, o Grupo Itacolomi situa-se na zona de charneira da estrutura dominante do sul do QF, que é o Sinclinal Dom Bosco. Essa estrutura, de orientação geral EW, é afetada na sua parte leste por um sistema de falhas de empurrão de traço curvo que promove o descolamento de várias escamas em direção a WNW (Dorr, 1969; Ribeiro e Alkmim, 1997). A estrutura geral das ocorrências do grupo reflete exatamente esse cenário tectônico. A investigação estrutural realizada na região revelou que as rochas Itacolomi descrevem um grande sinforme aberto com a charneira posicionada em 122/15. Superpõem-se a essa grande estrutura duas famílias de elementos tectônicos gerados em duas fases de deformações coaxiais, que incluem dobras de orientação NNE, falhas de empurrão - que promovem a duplicação dos estratos Itacolomi (Figura 4) -, além de zonas de cisalhamento dúcteis. A esses elementos maiores se associam uma foliação penetrativa e uma lineação de estiramento cujas orientações preferenciais são 138/28 e 121/26, respectivamente. Indicadores cinemáticos associados a todos esses elementos atestam transporte tectônico dirigido para WNW.

\section{MÉTODOS}

Para a caracterização dos espectros de idades dos grãos detríticos de zircão foram coletadas amostras ao longo dos perfis estratigráficos levantados nos blocos autóctone e alóctone, como indicado no mapa da Figura 4. Foram coletadas três amostras no bloco autóctone, duas em meta-arenitos (TR314 e TR316) e uma em um metaconglomerado (TR315), e duas amostras em meta-arenitos no bloco alóctone (TR310 e TR312). Cada amostra coletada, com cerca de $10 \mathrm{~kg}$ cada, foi submetida aos procedimentos para a separação dos minerais adequados a determinações
U-Pb no Laboratório de Preparação de Amostras para Geocronologia da Universidade Federal de Ouro Preto (LOPAG/UFOP). Estes incluíram:

- britagem e moagem;

- concentração de pesados por bateamento;

- primeira separação magnética com imã de mão para retirada de materiais muito magnéticos;

- segunda separação magnética utilizando separador eletromagnético FRANTZ;

- análise e seleção ótica dos grãos;

- confecção dos mounts;

- imageamento por meio de catodoluminescência (CL) e microscopia de varredura eletrônica no Instituto de Geociências da Universidade de São Paulo (IGc/USP).

As análises isotópicas foram feitas por meio da metodologia U-Pb em grãos detríticos de zircão via LA-ICPMS (Laser Ablation Inductively Coupled Plasma Mass Spectrometry) utilizando o LA-ICPMS Agilent 7700X acoplado ao Nd-YAG $(\lambda=213 \mathrm{~nm}$ ) Laser Ablation System (New Wave Laser). A ablação dos grãos foi realizada a uma frequência de $10 \mathrm{~Hz}$ e intensidade de $10 \mathrm{~J} / \mathrm{cm}^{2}$. O material atomizado foi levado por um fluxo de $\mathrm{He}$ e Ar e inserido ao ionizador de plasma.

As condições operacionais (tunning) do ICPMS e do laser utilizadas estão descritas na Tabela 2.

Tabela 2. Parâmetros de operação do LA-Q-ICP-MS.

\begin{tabular}{|c|c|}
\hline Espectômetro & Agilente 7700X \\
\hline Analisador de massa & Quadrupolo \\
\hline Potência RF (W) & 1550 \\
\hline Cone amostral & $\mathrm{Ni} ; 1,0 \mathrm{~mm}$ \\
\hline Cone skimmer & $\mathrm{Ni} ; 0,4 \mathrm{~mm}$ \\
\hline $\begin{array}{l}\text { Profundidade da } \\
\text { amostragem (cm) }\end{array}$ & 5 \\
\hline Gás plasma (L.min $\left.{ }^{-1}\right)$ & 15 \\
\hline Gás auxiliar (L.min-1) & 1,2 \\
\hline Gás opcional (L.min-1) & 1 \\
\hline Gás carregador (L.min'-1) & $1,00-1,10$ \\
\hline $\begin{array}{l}\text { Tempo de integração por } \\
\text { massa (ms) }\end{array}$ & 10 \\
\hline $\mathrm{ThO}^{+} / \mathrm{Th}^{+}(\%)$ & $<0,5$ \\
\hline Isótopos & $\begin{array}{c}{ }^{204} \mathrm{~Pb},{ }^{207} \mathrm{~Pb},{ }^{206} \mathrm{~Pb},{ }^{208} \mathrm{~Pb}, \\
{ }^{232} \mathrm{Th},{ }^{238} \mathrm{U},{ }^{235} \mathrm{U}\end{array}$ \\
\hline Ablação a laser & New Wave UP - 213 \\
\hline Frequência $(\mathrm{Hz})$ & 10 \\
\hline Fluência $\left(\mathrm{J} / \mathrm{cm}^{2}\right)$ & 10 \\
\hline Energia (\%) & 50 \\
\hline Varredura & Spot \\
\hline Área de ablação $(\mu \mathrm{m})$ & $30-40$ \\
\hline
\end{tabular}

Fonte: adaptada de Takenaka (2013). 
A aquisição dos dados foi feita por meio de consecutivas leituras crescentes da razão massa/carga e, posteriormente, foram reduzidas por meio do programa Glitter (GEMOC Laser ICP-MS Total Trace Element Reduction). Um detalhamento mais profundo sobre a instrumentação e a redução de dados pode ser encontrado em Hirata e Nesbitt (1995), Van Achterbergh et al. (2001), Jackson et al. (2004), Frei e Gerdes (2009) e Takenaka (2013).

Os resultados geocronológicos oriundos do LA-ICP-MS (Apêndices 1, 2, 3, 4 e 5) foram tratados utilizando o suplemento Isoplot 3.6 (Ludwig, 2008) no software Microsoft Excel, e foram gerados diagramas de concórdia, histogramas de distribuição e diagramas das médias das idades.

\section{RESULTADOS OBTIDOS}

O imageamento por CL e microscopia de varredura eletrônica revelou, em todas as amostras, cristais de zircão arredondados a subarredondados com características típicas de grãos detríticos (Figura 6). Os cristais são, em sua maioria, subédricos e comumente encontram-se fraturados ou com as bordas fragmentadas. Possuem coloração acastanhada e, em geral, são translúcidos. O comprimento dos grãos varia entre 50 e $350 \mu \mathrm{m}$, sendo os maiores encontrados nas amostras TR310 e TR312, provenientes dos meta-arenitos do bloco alóctone do Pico do Itacolomi. A maior parte apresenta-se pouco alongada, com proporção média entre comprimento e largura de 2:1. Exibem zoneamento oscilatório com poucos exemplares sem estruturação interna ou difusa.

\section{Amostra TR 316 (UTM: 657013 / 7740010), meta-arenito com estratitificação cruzada acanalada, base da sucessão autóctone}

O histograma de distribuição de idades de 82 grãos apresenta padrão polimodal com pico em 2167 Ma (Figura 7A), que supera em aproximadamente cinco vezes os picos menores. Atrelado a este, tem-se outro em torno 2252 Ma relativo a 14 grãos. Uma concentração bem menos expressiva fica em torno da idade de $2807 \mathrm{Ma}$. Utilizando o conjunto de idades dos oito grãos de zircão mais jovens, o suplemento isoplot forneceu a idade média de $2161 \pm 7$ Ma com 95\% de confiabilidade (Figura 7B).

\section{Amostra TR 315 (UTM: 657268 / 7739775), matriz de metaconglomerado suportado pelos clastos, porção intermediária da sucessão autóctone}

O total de 53 grãos de zircão foi usado para composição do histograma, o qual apresenta um padrão de distribuição polimodal com pico em $2197 \mathrm{Ma}$, que supera em até três vezes os picos menores e é gerado a partir de dez análises. Picos secundários ocorrem de forma menos expressiva, com no máximo quatro análises, com destaque para idades 2914 e 3207 Ma (Figura 8A).

Utilizando o conjunto de sete idades dos grãos de zircão mais jovens, o suplemento isoplot indicou a idade de $2143 \pm 08$ Ma com 95\% de confiabilidade (Figura 8B). Um único grão apresentou a idade mais jovem de $2132 \pm 25 \mathrm{Ma}$.
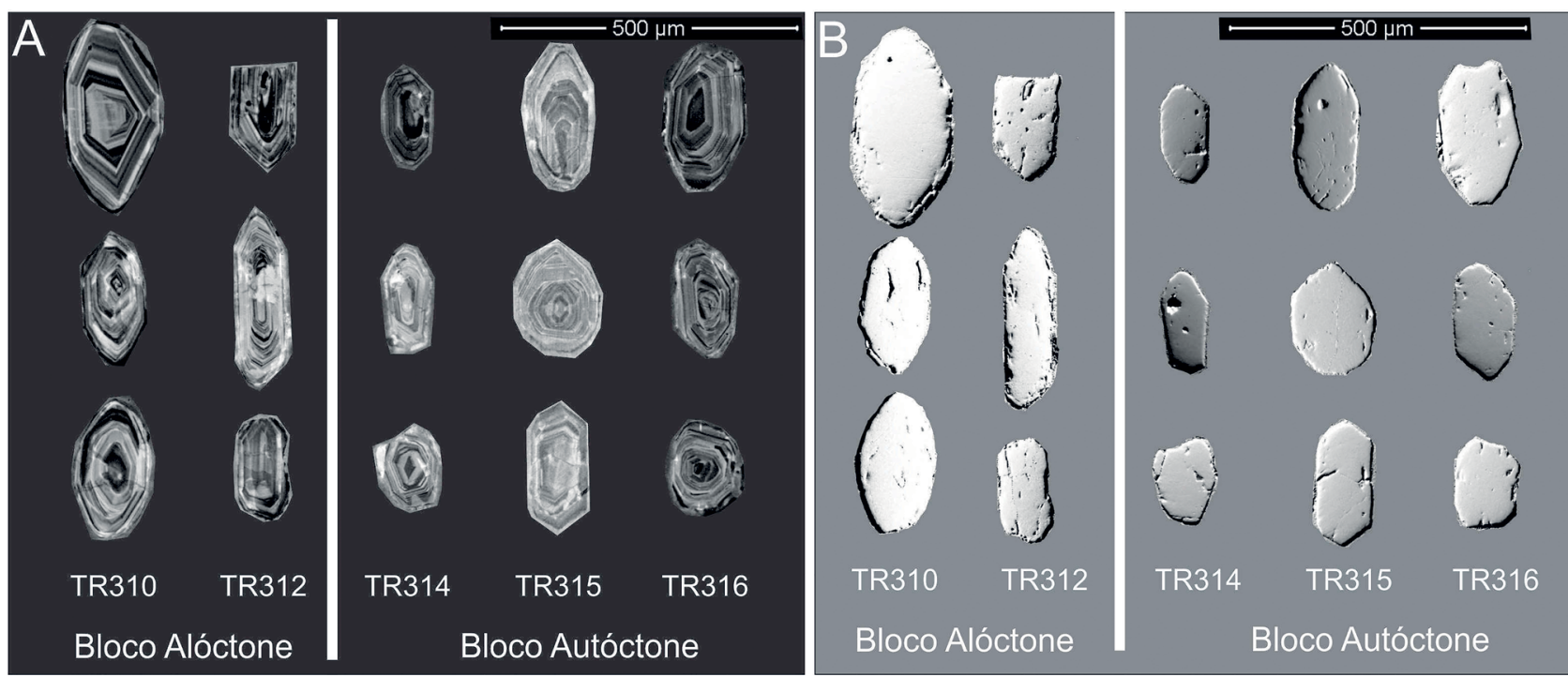

Figura 6. Imagens dos cristais de zircão típicos do Grupo Itacolomi por (A) catodoluminescência e (B) microscópio de varredura eletrônica de elétrons secundários. Notar as diferenças na relação comprimento/largura entre os cristais de zircão do bloco alóctone (TR 310 e TR 312) e do bloco autóctone (TR 314, TR 315 e TR 316). 
Amostra TR 314 (UTM: 657356 / 7739832), meta-arenito com estratitificação cruzada acanalada, porção intermediária da sucessão autóctone

Nesta amostra, foram obtidas 58 idades concordantes, que lançadas no diagrama de frequência, resultaram em uma distribuição polimodal com o pico principal, fornecido por dez análises, em $2203 \mathrm{Ma}$. Um pico menos representativo ocorre ainda entre 2914 e $2960 \mathrm{Ma}$ (Figura 9A).

Para o conjunto dos cinco grãos de zircão mais jovens, o suplemento isoplot indicou a idade de $2144 \pm 15$ Ma com $95 \%$ de confiabilidade (Figura 9B). Um único grão apresentou a idade mais jovem de $2126 \pm 20 \mathrm{Ma}$.

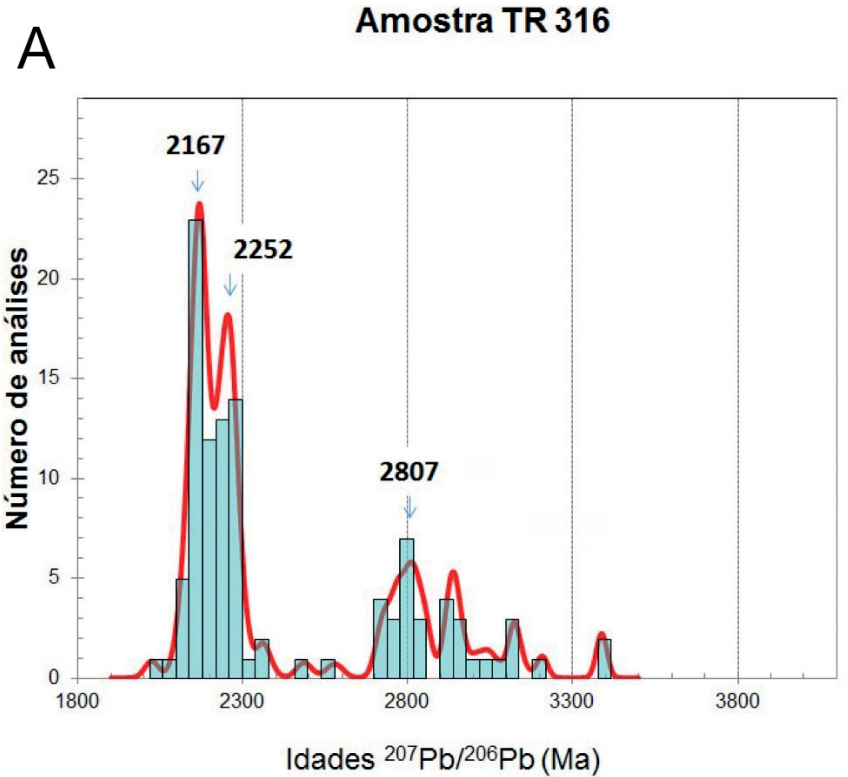

B

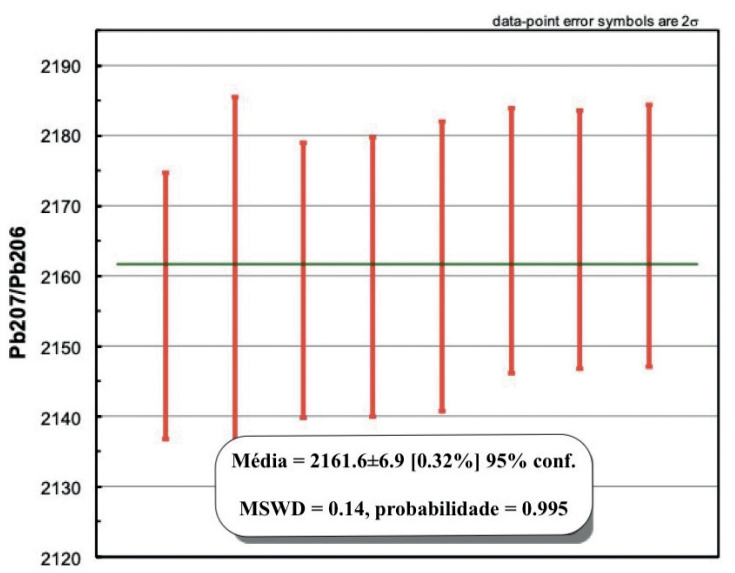

Figura 7. (A) Histograma e curva de frequência de idades $\mathrm{Pb}-\mathrm{Pb}$ de grãos detríticos de zircão (amostra TR 316); (B) média das idades mais jovens obtidas na amostra TR 316.

A

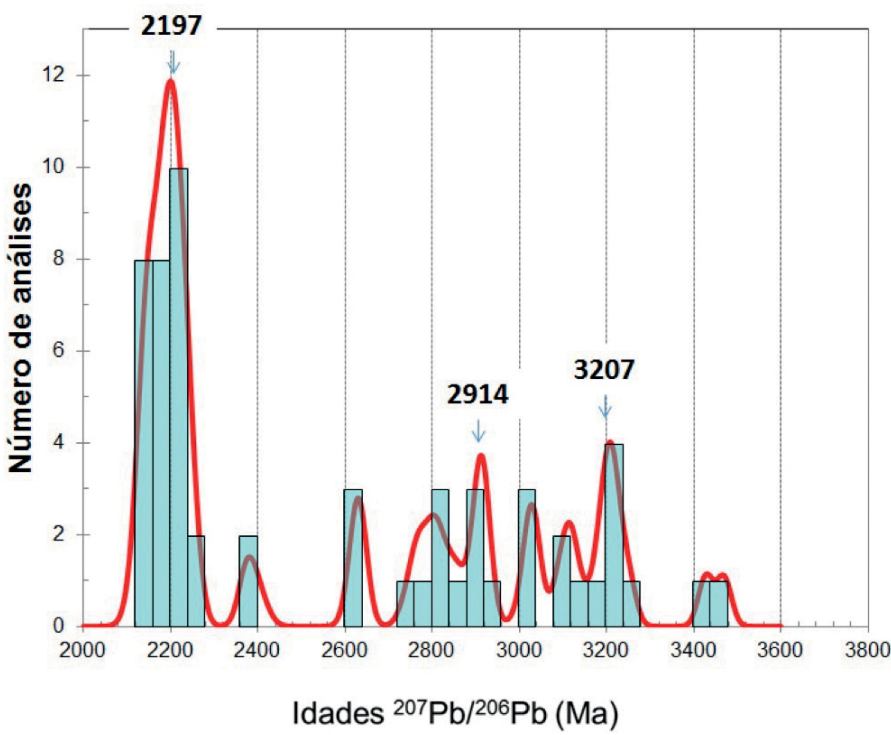

B

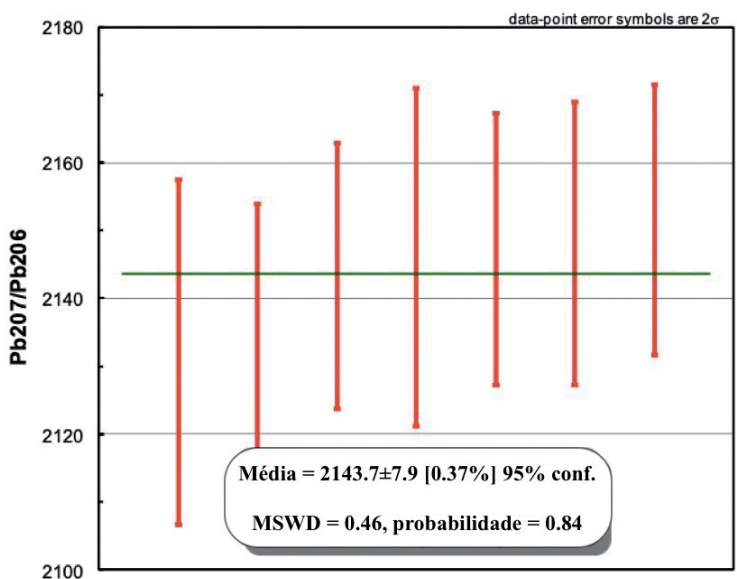

Figura 8. (A) Histograma e curva de frequência de idades $\mathrm{Pb}-\mathrm{Pb}$ de grãos detríticos de zircão (amostra TR 315); (B) média das idades mais jovens obtidas na amostra TR 315. 


\section{Amostra TR 312 (UTM: 659259 / 7740363), meta-arenito, bloco alóctone}

O histograma gerado a partir de 82 idades concordantes apresenta padrão polimodal com pico de 2201 Ma relativo a nove grãos. Outro pico expressivo é o de $2894 \mathrm{Ma}$. Picos subordinados ocorrem entre 2661 e 2704 Ma com seis análises. Ocorrem ainda picos menores com até duas análises para idades acima de $3200 \mathrm{Ma}$ (Figura 10A).

Utilizando o conjunto de idades dos três grãos mais jovens, o suplemento isoplot indicou a idade de $2129 \pm 11 \mathrm{Ma}$ com
95\% de confiabilidade (Figura 10B), que pode ser tomada como a idade máxima de sedimentação.

\section{Amostra TR 310 (UTM: 659741 / 7740173), meta-arenito, fácies mAca, bloco alóctone}

Desta amostra, coletada no Pico do Itacolomi, foram obtidos 79 grãos com idades concordantes, cujas idades definem um espectro polimodal com o pico principal em $2156 \mathrm{Ma} \mathrm{e}$ picos secundários em 2309, 2700 e $3074 \mathrm{Ma}$ (Figura 11A). Utilizando o conjunto de idades dos 11 grãos de zircão mais

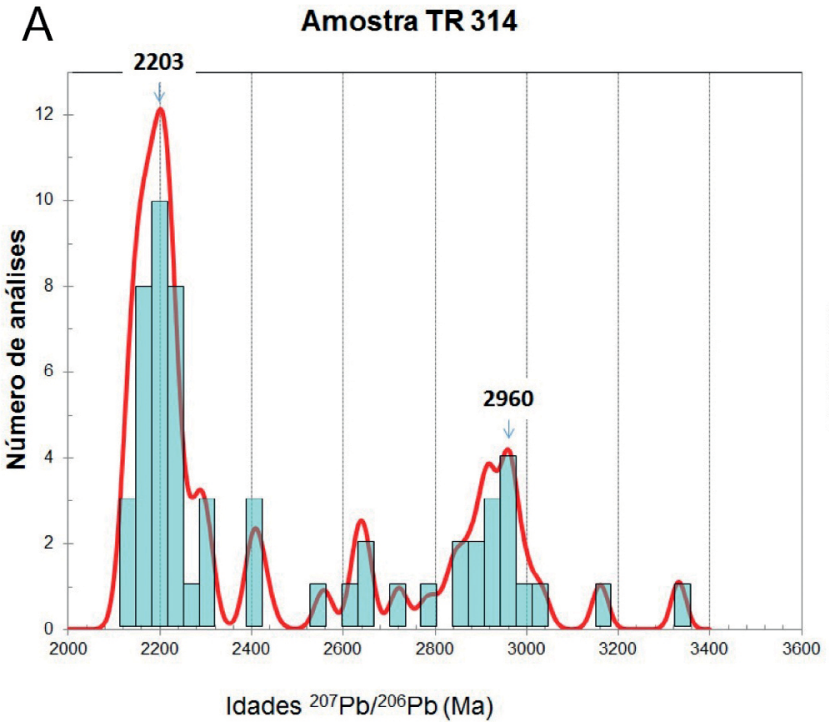

B

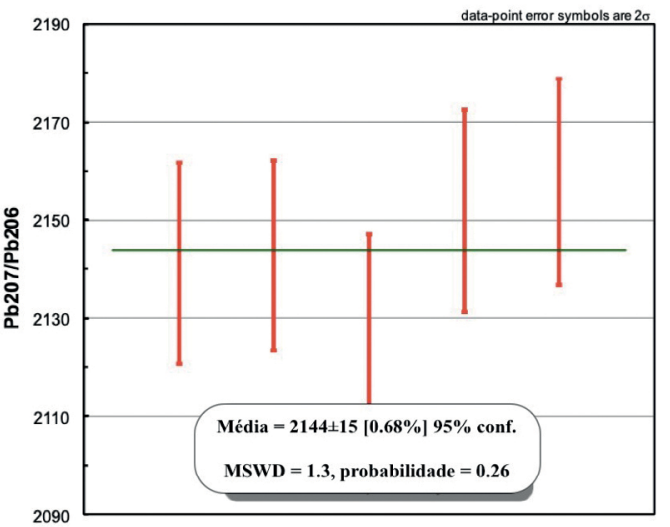

Figura 9. (A) Histograma e curva de frequência de idades $\mathrm{Pb}-\mathrm{Pb}$ de grãos detríticos de zircão (amostra TR 314); (B) média das idades mais jovens obtidas na amostra TR 314.

A

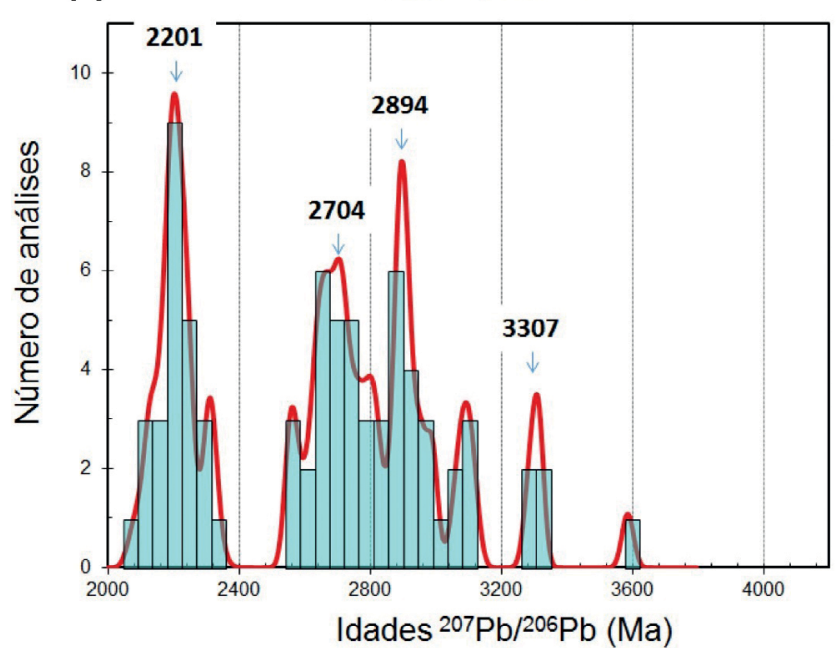

B

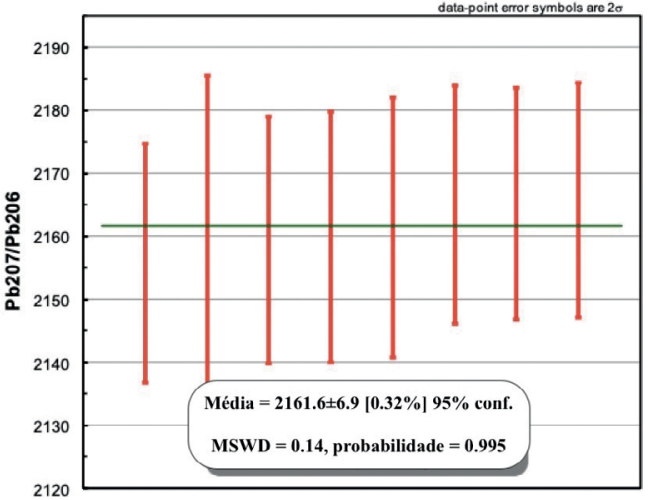

Figura 10. (A) Histograma e curva de frequência de idades $\mathrm{Pb}-\mathrm{Pb}$ de grãos detríticos de zircão (amostra TR 312 ); (B) média das idades mais jovens obtidas na amostra TR 312. 
jovens, obteve-se a idade de $2148 \pm 13 \mathrm{Ma}$ (Figura 11B), que pode ser tomada como a idade máxima de deposição da unidade. Em um único grão, verificou-se a idade mais nova de $2098 \pm 21 \mathrm{Ma}$.

\section{DISCUSSÃO DOS RESULTADOS}

Os dados obtidos possibilitam estimar com maior segurança a idade máxima de deposição do Grupo Itacolomi e tecer considerações a respeito das suas áreas fonte, da ambiência tectônica e da idade de deformação.

\section{Sobre a idade do Grupo Itacolomi}

Os espectros de idades obtidos nas diversas amostras coletadas podem ser, em primeiro lugar, separados em dois grupos: aqueles relativos ao bloco autóctone e aqueles relativos aos meta-arenitos alóctones do Pico do Itacolomi.

Comparando-se, primeiramente, os dois espectros (Figura 12), percebe-se que aqueles relativos à sucessão autóctone são unimodais com picos principais de idades paleoproterozoicas em torno de 2203, 2197 e $2167 \mathrm{Ma}$, e concentrações apenas subordinadas de idades arqueanas. Já os meta-arenitos do bloco alóctone geraram diagramas polimodais com importantes concentrações de idades arqueanas em torno de 2700, 2900, 3100 e $3300 \mathrm{Ma}$, em associação com um ou dois picos principais de idades paleoproterozoicas. Tais diferenças podem resultar de uma alimentação distinta, resultante de diferentes posições originais ocupadas pelos pacotes na Bacia Itacolomi.

Quando se examinam as idades mais jovens, isto é, os picos principais e as idades máximas de sedimentação, conclui-se que não se pode fazer a distinção entre as duas sucessões. Tendo em vista os erros, elas podem ser consideradas equivalentes. A idade máxima de sedimentação da unidade relativa à amostra TR312, coletada no pacote alóctone do Pico, é de $2129 \pm 11 \mathrm{Ma}$. Além disso, relacionando-se as amostras datadas à sua posição na sequência estratigráfica, não são evidenciadas variações significativas.

Em relação aos dados obtidos em estudos anteriores, isto é, por Machado et al. (1996), Hartmann et al. (2006) e Jordt-Evangelista et al. (2015) (Tabela 3), tanto na área tipo como em sucessões de quartzitos correlacionados ao Grupo Itacolomi, pode-se, em primeiro lugar, verificar que os espectros obtidos são similares aos caracterizados no presente estudo.

Embora algumas das idades obtidas por esses autores sejam ligeiramente mais jovens que as dos dados obtidos neste trabalho, essas idades podem ser consideradas equivalentes, uma vez que se encontram dentro do erro analítico.

Vale mencionar que as idades obtidas para o Grupo Sabará (Machado et al., 1996; Harttmann et al., 2006) são muito próximas às idades encontradas para o Grupo Itacolomi. A idade $2125 \mathrm{Ma}$ é considerada a idade máxima de deposição para o Grupo Sabará, como indicam os resultados obtidos por Machado et al. $(1992,1996)$. Os dados obtidos por esses autores apresentam um espectro polimodal com dois
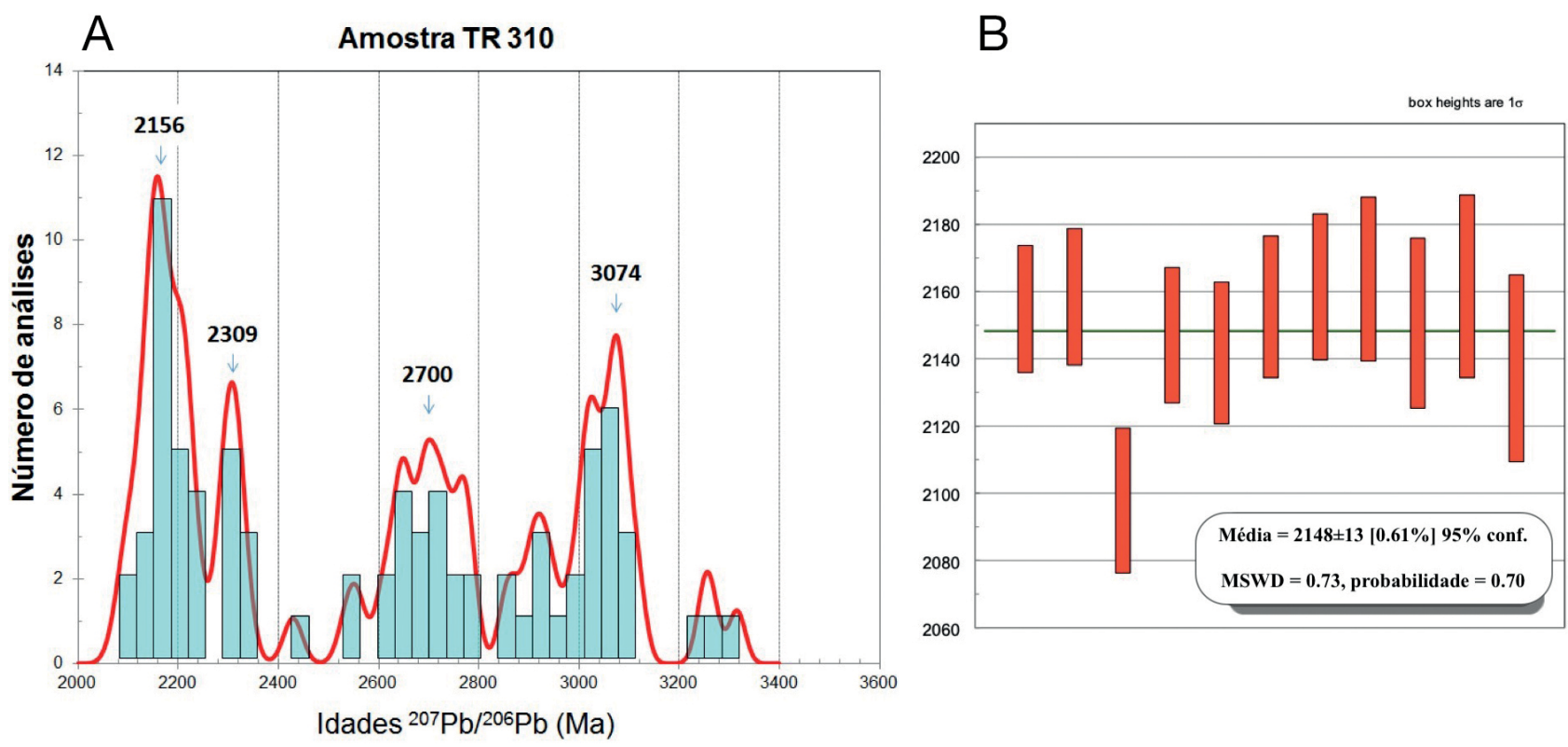

Figura 11. (A) Histograma e curva de frequência de idades $\mathrm{Pb}-\mathrm{Pb}$ de grãos detríticos de zircão (amostra TR 310 ); (B) média das idades mais jovens obtidas na amostra TR 310. 
picos principais, entre 2650 e $2950 \mathrm{Ma}$ e de 2160 a 2320 $\mathrm{Ma}$, e a idade de 2120 Ma representaria o fechamento da Bacia Minas e uma inversão tectônica com a deposição sin-orogênica do Grupo Sabará (Dorr, 1969; Alkmim e Marshak, 1998).

Além da estimativa da idade máxima de deposição para o grupo, pode-se fazer aqui também uma consideração a respeito da sua idade mínima por meio da idade do dique de rocha máfica que corta os meta-arenitos basais na porção oeste da serra (vide mapa da Figura 4). Silva et al. (1995) dividem os enxames de diques máficos presentes no QF em três grupos de acordo com os eventos de magmatismo básico que ocorreram nessa região. $\mathrm{O}$ pulso mais antigo representado por diques de orientação NW-SE, que provavelmente estaria relacionado com o corpo que corta o Grupo Itacolomi, foi datado em $1714 \pm 05 \mathrm{Ma}$.

\section{Sobre a proveniência das rochas do Grupo Itacolomi}

Examinando-se as distribuições de idades, tanto do bloco autóctone quanto do bloco alóctone do pico, observa-se que suas fontes volumetricamente mais importantes são de rochas paleoproterozoicas com idades compreendidas entre 2350 e $2129 \mathrm{Ma}$, isto é, geradas quase que totalmente durante o Período Riaciano. Quando se considera o contexto regional no qual se insere a área tipo do Grupo Itacolomi, conclui-se que as suas potenciais fontes seriam o Cinturão Mineiro (Seixas et al., 2013; Teixeira et al., 2015; Barbosa et al., 2015), o Complexo Mantiqueira (Jordt-Evangelista et al., 2000; Heilbron et al., 2010; Silva et al., 2016; Fonseca, 2017) e até mesmo o Complexo Juiz de Fora (Noce et al., 2007; Silva et al., 2016) (Figura 1). Tendo-se em mente que a literatura prevê, pelo menos para o Cinturão Mineiro e o Complexo Juiz de Fora, uma origem intraoceânica e alóctone, a alimentação da região do QF por essas fontes só poderia se concretizar após a sua colagem e soerguimento na margem do bloco arqueano precursor do Cráton do São Francisco. Ou seja, o Grupo Itacolomi teria se depositado após ou no máximo durante a Orogenia Transamazônica cujo clímax na região se situa entre 2100 e $2080 \mathrm{Ma}$ (Aguilar et al., 2017). Além disso, a presença marcante de clastos

Tabela 3. Idades de máxima deposição para o Grupo Itacolomi encontradas por Machado et al. (1996), Hartmann et al. (2006), Jordt-Evangelista et al. (2015) e no presente trabalho.

\begin{tabular}{lc}
\hline Autor/amostra & Idade (Ma) \\
\hline Machado et al. (1996) / ITAC-93 & $2059 \pm 58$ \\
Hartmann et al. (2006) / (6) & $2143 \pm 16$ \\
Jordt-Evangelista et al. (2015) / JP-F02 & $2087 \pm 19$ \\
Amostra TR 316 & $2161 \pm 07$ \\
Amostra TR 315 & $2143 \pm 08$ \\
Amostra TR 314 & $2144 \pm 15$ \\
Amostra TR 312 & $2129 \pm 11$ \\
Amostra TR 310 & $2148 \pm 13$ \\
\hline
\end{tabular}

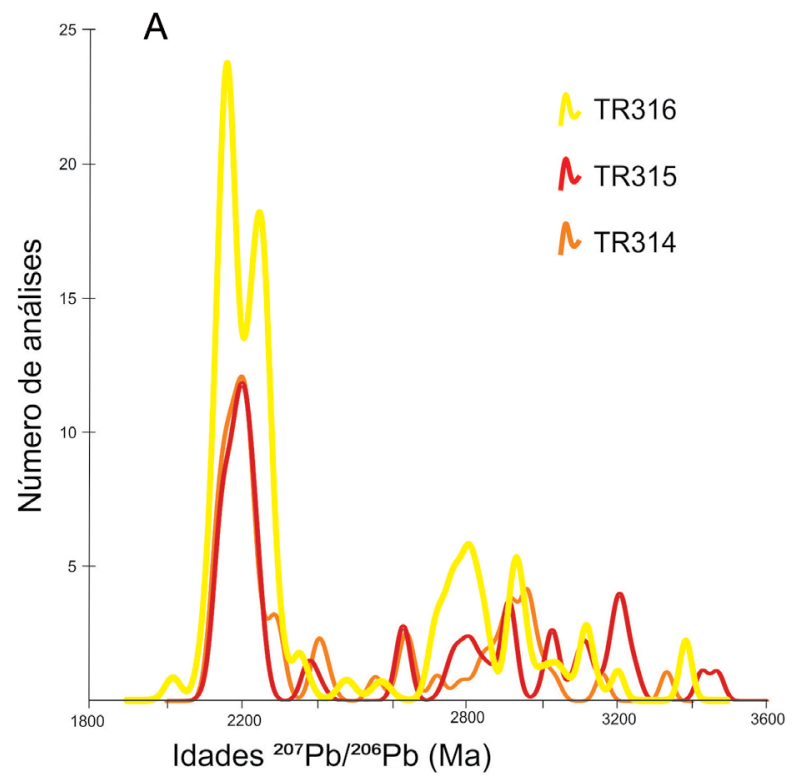

B

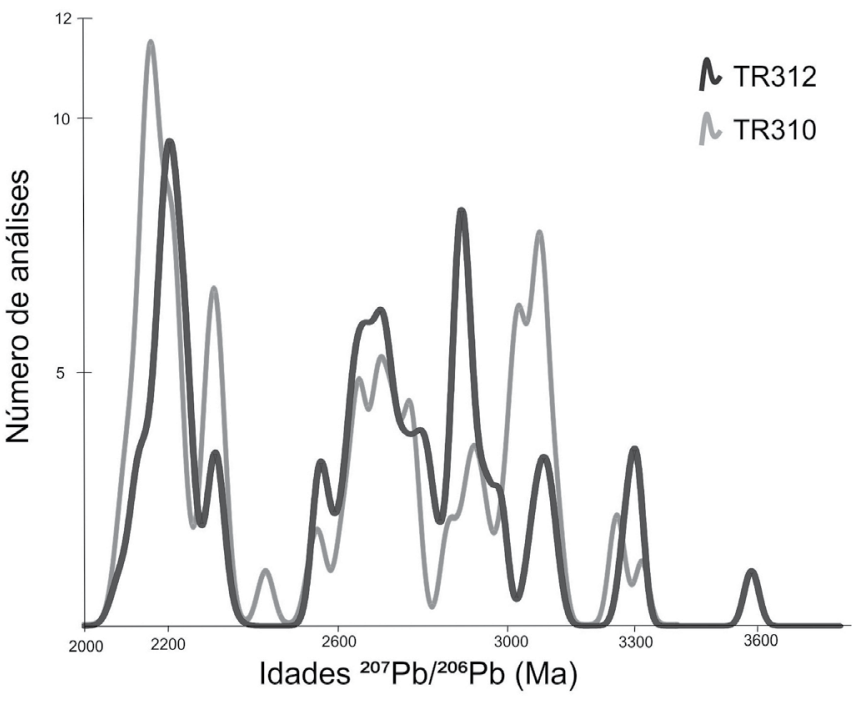

Figura 12. (A) Diagramas de frequência com distribuição de idades para as amostras da sucessão autóctone; (B) meta-arenitos da porção alóctone (Pico do Itacolomi). 
de formação ferrífera bandada, muito abundantes na fácies Santo Antônio, indicam como outras potenciais fontes as unidades do Supergrupo Minas.

Outras fontes de sedimentos representadas por picos subordinados tanto nas rochas do pico quanto no bloco autóctone estariam relacionadas aos eventos magmáticos arqueanos detectados no QF (Farina et al., 2016; Martínez-Dopico et al., 2017):

- Evento Santa Bárbara (3200-3220 Ma), correlacionado com picos nas amostras TR 315 e TR 316;

- Evento Rio das Velhas I (2850-2930 Ma), correlacionado com picos nas amostras TR 312 e TR 315;

- Evento Rio das Velhas II (2760-2800 Ma), correlacionado com picos na amostra TR 310;

- Evento Mamona I (2750-2680 Ma), correlacionado com picos nas amostras TR 310, TR 312 e TR 314;

- Evento Mamona II (2620-2580 Ma), correlacionado com picos nas amostras TR 310, TR 312, TR 314 e TR 316.

\section{Sobre o ambiente tectônico da Bacia Itacolomi}

Utilizando o método de curvas cumulativas de idades (Cawood et al., 2012; Cawood et al., 2013; Moreira et al., 2016) para as amostras do Grupo Itacolomi, conclui-se, de forma geral, uma tendência para o campo " $A$ " (bacias de margens convergentes) e também na zona de influência do campo "B" (bacias de ambientes de colisão continental) (Figura 13). As amostras TR 310 e TR 312 do Pico

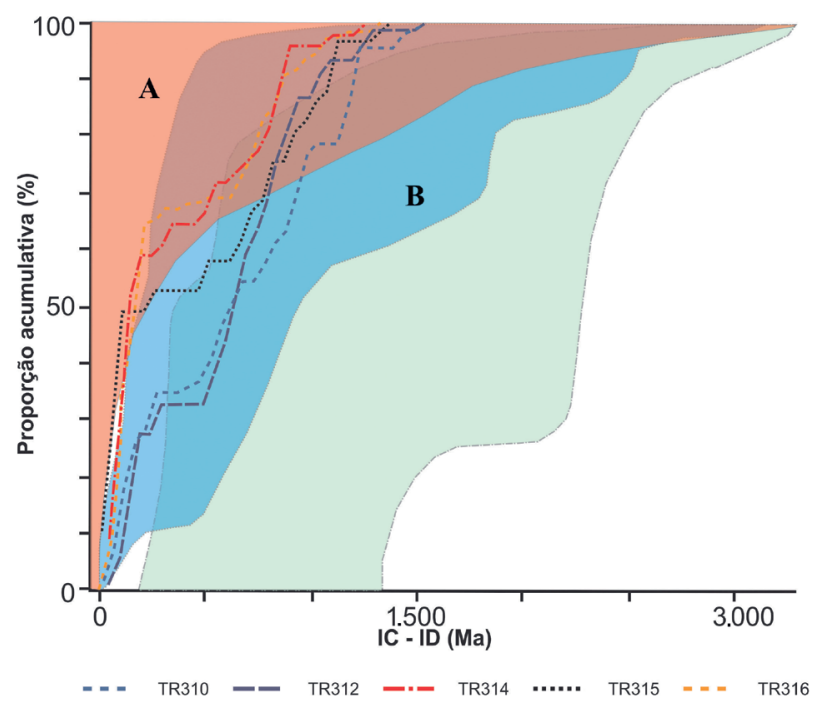

IC: idade de cristalização; ID: idade de deposição.

Figura 13. Curvas cumulativas de idades para as amostras datadas do Grupo Itacolomi, lançadas no gráfico de Cawood et al. (2012), o qual tem na ordenada a porcentagem da proporção acumulativa, e na abscissa a diferença entre idade de cristalização e idade de deposição.
Itacolomi (bloco alóctone) possuem aproximadamente 70\% de proporção cumulativa exclusivamente no campo " $B$ ", ou seja, teriam sido originadas em ambientes de bacias de antepaís. Já as amostras TR 314, TR 315 e TR 316 (bloco autóctone) possuem, por sua vez, uma tendência para o campo "A", com mais de $60 \%$ exclusivo neste campo, e o restante na região de sobreposição. Essas amostras possuem tendências de terem sido formadas em uma bacia do tipo retroarco. Entretanto, em função da proporção acumulativa de 50\%, a amostra TR 315 migra drasticamente para o campo "B", retornando ao campo "A" na proporção de $70 \%$. Esse fato sugere transição de um ambiente ao outro. Tendo em mente a relação do Grupo Itacolomi com as suas potenciais unidades fonte anteriormente mencionadas, conclui-se que o seu ambiente é realmente duplo, ou seja, um domínio de antepaís desenvolvido na região de retroarco em relação aos centros magmáticos paleoproterozoicos representados pelo Cinturão Mineiro e pelo Complexo Mantiqueira.

\section{Sobre a idade da deformação do Grupo Itacolomi}

Outro aspecto a ser aqui discutido é a idade de deformação da unidade. Aguilar et al. (2017) identificaram em rochas do QF titanitas e monazitas que registram um evento termal entre 2080 e $1940 \mathrm{Ma}$, evento este não detectado nos grãos de zircão que apenas registram idades magmáticas. Ou seja, as temperaturas relacionadas a esse evento termal não seriam suficientes para alterar o sistema U-Pb do zircão. De acordo com os autores mencionados, esse evento termal estaria relacionado ao desenvolvimento das auréolas metamórficas na periferia dos domos do Bação, de Belo Horizonte e do Bomfim (Alkmim e Teixeira, 2017), e seria de natureza pós-colisional. No entanto, as idades mais jovens encontradas nos grãos de zircão do Grupo Itacolomi implicam que, como mencionado, os arcos Mantiqueira e do Cinturão Mineiro já estariam justapostos, soerguidos e expostos a sul e leste do QF, o que leva a crer que as rochas do grupo foram depositadas após o evento colisional Transamazônico, que ocasionou a conversão do QF em uma bacia de antepaís. Isso poderia ter, portanto, ocorrido sincronicamente com o evento termal detectado por Aguilar et al. (2017). Se correta essa interpretação, confirmar-se-iam, assim, as hipóteses de Barbosa (1959) e Dorr (1969) do caráter pós-orogênico (molassa) do Grupo Itacolomi. Porém, as rochas do grupo sofreram intensa deformação de natureza compressional, que não poderia, portanto, ser correlacionada ao Evento Transamazônico.

Como relatado, diques máficos cortam toda a sequência do $\mathrm{QF}$, e na localidade tipo do Grupo Itacolomi, ocorrem na porção NW com direção NW-SE (Figura 4). Esses diques, segundo Silva et al. (1995), possuem idades em torno de 1714 Ma e encontram-se deformados 
na área de estudo. Levando-se em consideração o que se conhece sobre a evolução da porção do Cráton do São Francisco e áreas adjacentes, pode-se supor com certa margem de segurança que essa deformação deve representar na região o evento Neoproterozoico Brasiliano. Como postulado por Chemale Jr. et al. (1994) e Alkmim e Marshak (1998), o Evento Brasiliano foi responsável pelo desenvolvimento de um cinturão de cavalgamentos com vergência para $\mathrm{W}$ em grande parte da área do $\mathrm{QF}$ e, especialmente, pela geração do sistema de falhas de empurrão do Sinclinal Dom Bosco (Chemale Jr. et al., 1991; Rolim e Alkmim, 2004).

\section{CONCLUSÕES}

Do estudo realizado sobre a estratigrafia, estrutural e geocronologia do Grupo Itacolomi em sua área tipo, pode-se concluir:

- A idade máxima de deposição do grupo fica em 2129 $\pm 11 \mathrm{Ma}$, a qual é consistente com as estimativas anteriormente feitas por Machado et al. (1996) e Hartmann et al. (2006);

- Apesar das diferenças nos espectros de idades, nas características morfológicas dos grãos de zircão e no acervo de minerais pesados detectados por Glöckner (1981), pode-se afirmar que os meta-arenitos alóctones do Pico do Itacolomi pertencem ao grupo homônimo. Fica assim confirmada a hipótese de Barbosa (1969) e Dorr (1969) e descartada a sugestão de Glöckner (1981) de que os meta-arenitos do Pico do Itacolomi seriam correlativos de unidades pré-Minas;

- Os sedimentos do Grupo Itacolomi possuem como fontes principais os granitoides do Cinturão Mineiro e dos complexos Mantiqueira e Juiz de Fora envolvidos na orogênese Riaciana. Além dessas, tem-se outras fontes, como as formações ferríferas bandadas, possivelmente, do Supergrupo Minas, presentes tanto na matriz quanto nos clastos dos conglomerados da fácies Santo Antônio.

\section{AGRADECIMENTOS}

Tiago Duque agradece a Fundação de Amparo à Pesquisa do Estado de Minas Gerais (FAPEMIG) a bolsa de estudo e a Universidade Federal de Ouro Preto (UFOP) as análises isotópicas. Fernando Flecha de Alkmim e Cristiano Lana agradecem ao Conselho Nacional de Desenvolvimento Científico e Tecnológico (CNPq) a bolsa de produtividade em pesquisa que usufruem. Os autores agradecem também aos revisores anônimos que contribuíram para consideráveis melhorias no manuscrito original.

\section{REFERÊNCIAS}

Aguilar, C., Alkmim, F. F., Lana, C., Farina, F. (2017). Palaeoproterozoic assembly of the São Francisco craton, SE Brazil: New insights from $\mathrm{U}-\mathrm{Pb}$ titanite and monazite dating. Precambrian Research, 289, 95-115. https://doi. org/10.1016/j.precamres.2016.12.001

Alkmim, F. F. (1987). Modelo deposicional para a sequência dos metassedimentos da Serra de Ouro Branco, Quadrilátero Ferrífero, Minas Gerais, Paper Sistemas Deposicionais no Pré-Cambriano. Simpósio sobre Sistemas Deposicionais no PréCambriano, 47-68. Anais... Ouro Peto: SBG, Núcleo-MG.

Alkmim, F. F., Marshak, S. (1998). Transamazonian Orogeny in the Southern São Francisco Craton Region, Minas Gerais, Brazil: evidence for Paleoproterozoic collision and collapse in the Quadrilátero Ferrífero. Precambrian Research, 90(1-2), 29-58. https://doi.org/10.1016/S0301-9268(98)00032-1

Alkmim, F. F., Teixeira, W. (2017). The Paleoproterozoic Mineiro Belt and the Quadrilátero Ferrífero. In: M. Heilbron, U.G. Cordani, F.F. Alkmim (Eds.), São Francisco Craton, Eastern Brazil: Tectonic Genealogy of a Miniature Continent. Suíça: Springer International Publishing. p. 71-94. https:// doi.org/10.1007/978-3-319-01715-0_5

Almeida, L. G., Castro, P. T. A., Endo, I., Fonseca, M. A. (2005). O Grupo Sabará no Sinclinal Dom Bosco, Quadrilátero Ferrífero: uma revisão estratigráfica. Revista Brasileira de Geociências, 35(2),177-186.

Ávila, C. A., Teixeira, W., Bongiolo, E. M., Dussin, I. A., Vieira, T. A. T. (2014). Rhyacian evolution of subvolcanic and metasedimentary rocks of the southern segment of the Mineiro belt, São Francisco craton, Brazil. Precambrian Research, 243, 221-251. https://doi.org/10.1016/j. precamres.2013.12.028

Baltazar, O. F., Zucchetti, M. (2007). Lithofacies associations and structural evolution of the Archean Rio das Velhas greenstone belt, Quadrilátero Ferrífero, Brazil: a review of the setting of gold deposits. Ore Geology Reviews, 32(3-4), 471-499. https://doi.org/10.1016/j. oregeorev.2005.03.021

Barbosa, A. L. M. (1959). Série Itacolomi. Publ. Especial DNPM, 1, 20-22. Rio de Janeiro: DNPM.

Barbosa, A. L. M. (1968). Contribuições recentes à geologia do Quadrilátero Ferrifero. Ouro Preto: Editora da Escola de Minas da Universidade Federal de Ouro Preto. 47 p. 
Barbosa, A. L. M. (1969). Mapa geológico das quadrículas de Mariana e Rio de Bandeiras, Minas Gerais, Brazil. Washington, USGS/DNPM. Professional Paper 641-A, plate 10.

Barbosa, N. S., Teixeira, W., Ávila, C. A., Montecinos, P. M., Bongiolo, E. M. (2015). 2.17-2.10 Ga plutonic episodes in the Mineiro belt, São Francisco Craton, Brazil: U-Pb ages, geochemical constraints and tectonics. Precambrian Research, 270, 204-225. https://doi.org/10.1016/j.precamres.2015.09.010

Barbosa, O. (1949). Contribuição a geologia do centro de Minas Gerais. Mineração e Metalurgia, 14(79), 3-19.

Brueckner, H. K., Cunningham, D., Alkmim, F. F., Marshak, S. (2000). Tectonic implications of Precambrian Sm-Nd dates from the Southern São Francisco craton and adjcent Araçuaí and Ribeira belts, Brazil. Precambrian Research, 99, 255-269. https://doi.org/10.1016/S0301-9268(99)00065-0

Cawood, P. A., Hawkesworth, C. J., Dhuime, B. (2012). Detrital zircon record and tectonic setting. Geology, 40(10), 875-878. https://doi.org/10.1130/G32945.1

Cawood, P. A., Hawkesworth, C. J., Dhuime, B. (2013). The continental record and the generation of continental crust. Geological Society of America Bulletin, 125(1-2), 14-32. https://doi.org/10.1130/B30722.1

Chemale Jr., F., Rosière, C. A., Endo, I. (1991). Evolução tectônica do Quadrilátero Ferrífero, Minas Gerais: um modelo. Pesquisas, 18(2), 104-127. https://doi. org/10.22456/1807-9806.21350

Chemale Jr., F., Rosière, C. A., Endo, I. (1994). The tectonic evolution of the Quadrilátero Ferrífero, Minas Gerais, Brazil. Precambrian Research, 65(1-4), 25-54. https://doi. org/10.1016/0301-9268(94)90098-1

Derby, O. A. (1906). The Serra do Espinhaço, Brazil. The Journal of Geology, 14(5), 374-401.

Dorr, J. V. N. (1969). Physiographic, stratigraphic and structural development of the Quadrilátero Ferrífero, Minas Gerais, Brazil. Geological Survey. Professional Paper 641-A. 110p. https://doi.org/10.3133/pp641A

Duque, T. R. F. (2018). O Grupo Itacolomi em sua área tipo: estratigrafia, estrutura e significado tectônico. Dissertação (Mestrado). Ouro Preto: Universidade Federal de Ouro Preto, UFOP. 102p.

Eschwege, W. L. V. (1811). Carta petrográfica e orográfica com hum perfil das rochas de Villa Rica para o Arrayal do
Tejuco e idem do Arrayal do Tejuco pelo Caminho do Sabará para Villa Rica. Arqu. Hist. do Exército (RJ), manuscrito.

Farina, F., Albert, C., Martínez-Dopico, C., Aguilar Gil, C., Moreira, H., Hippertt, J. P., Cutts, K., Alkmim, F. F., Lana, C. (2016). The Archean-Paleoproterozoic evolution of the Quadrilatero Ferrifero (Brasil): Current models and open questions. Journal of South American Earth Sciences, 68, 4-21. https://doi.org/10.1016/j.jsames.2015.10.015

Ferreira, A. F., Lazarin, H. A. (1993). Caracterização litoestrutural e geomorfológica da região do Pico do Itacolomi, Ouro Preto. Monografia (Graduação). Ouro Preto: Universidade Federal de Ouro Preto, UFOP. 54p.

Fonseca, G. M. (2017). Petrogênese de rochas metaultramáficas do Quadrilátero Ferrífero e adjacências e geocronologia de terrenos associados. Dissertação (Mestrado). Ouro Preto: Escola de Minas da Universidade Federal de Ouro Preto, 108p.

Frei, D., Gerdes, A. (2009). Precise and accurate in situ U-Pb dating of zircon with high sample throughput by automated LA-SF-ICP- MS: Chemical Geology, 261(3-4), 261-270. https://doi.org/10.1016/j.chemgeo.2008.07.025

Girardi, V. A. V., Teixeira, W., Mazzuccheli, M., Oliveira, E. P., Costa, P. C. C. (2017). Mafic dykes: Petrogenesis and tectonic inferences. In: M. Heilbron, U. G. Cordani, F. F. Alkmim (Eds.), São Francisco Craton, Eastern Brazil: Tectonic Genealogy of a Miniature Continent (p. 145-169). Suíça: Springer International Publishing. https://doi. org/10.1007/978-3-319-01715-0_8

Glöckner, R. H. (1981). Lithostratigraphie, Sedimentologie, Tektonik und Metamorphose der proterozoischen Itacolomi. Serie bei Ouro Preto, Minas Gerais, Brasilien. Dissertação. Institut für Geologie und Paläontologie, 221p.

Gorceix. H. (1883). Estudo chimico e mineralogico das rochas dos arredores de Ouro Preto. Ouro Preto, Escola de Minas, Annales, 2, 5-22.

Guild, P. W. (1957). Geology and mineral resources of the Congonhas district, Minas Gerais, Brazil. Washington, Geological Survey. Professional Paper, 290. 89p. https:// doi.org/10.3133/pp290

Guimarães, D. (1931). Contribuição à geologia do Estado de Minas Gerais. Rio de Janeiro. Boletim, 35. 36p.

Harder, E. C., Chamberlin, R. T. (1915). The Geology of Central Minas Gerais, Brazil. Part I. Journal of Geology, 23(4), 341-378. 
Hartmann, L. A., Endo, I., Suita, M. T. F., Santos, J. O. S., Frantz, J. C., Carneiro, M. A., Naughton, N. J., Barley, M. E. (2006). Provenance and age delimitation of Quadrilátero Ferrífero sandstones based on zircon U-Pb isotopes. Journal of South American Earth Sciences, 20(4), 273-285. https:// doi.org/10.1016/j.jsames.2005.07.015

Heilbron, M., Duarte, B. P., Valeriano, C. M., Simonetti, A., Machado, N., Nogueira, J. R. (2010). Evolution of reworked Paleoproterozoic basement rocks within the Ribeira belt (Neoproterozoic), SE-Brazil, based on U-Pb geochronology: implications for paleogeographic reconstructions of the São Francisco-Congo paleocontinent. Precambrian Research, 178(1-4), 136-148. https://doi.org/10.1016/j. precamres.2010.02.002

Hirata, T., Nesbitt, R. W. (1995). U-Pb isotope geochronology of zircon: evaluation of the laser probe-inductively coupled plasma-mass spectrometry technique. Geochimica et Cosmochiica Acta, 59(12), 2491-2500. https://doi. org/10.1016/0016-7037(95)00144-1

Jackson, S. E., Pearson, N. J., Griffin, W. L., Belousova, E. A. (2004). The application of laser ablation-inductively coupled plasma-mass spectrometry to in situ U-Pb zircon geochronology. Chemical Geology, 211(1-2), 47-69. https:// doi.org/10.1016/j.chemgeo.2004.06.017

Jordt-Evangelista, H., Alvarenga, J. P. M., Lana, C. (2015). Petrography and geochronology of the Furquim Quartzite, an eastern extension of the Itacolomi Group (Quadrilátero Ferrífero, Minas Gerais). REM: Revista Escola de Minas, 68(4), 393-399. https://doi.org/10.1590/0370-44672015680054

Jordt-Evangelista, H., Peres, G. G., Macambira, M. J. B. (2000). $\mathrm{Pb} / \mathrm{Pb}$ single-zircon dating of Paleoproterozoic calcalkaline/alkaline magmatism in the southern São Francisco Craton region, Brazil. Revista Brasileira de Geociências, 30(1), 174-176. https://doi.org/10.25249/0375-7536.2000301174176

Lacourt, F. (1935). Resumo da Geologia da Folha Ouro Preto: Brasil. Anais... Ouro Preto: Escola Nacional de Minas e Metalurgia da Universidade, n. 27, 48p.

Lana, C., Alkmim, F. F., Armstrong, R., Scholz, R., Romano, R., Nalini Jr., H. A. (2013). The ancestry and magmatic evolution of Archaean TTG rocks of the Quadrilátero Ferrífero province, southeast Brazil. Precambrian Research, 231, 157-173. https://doi.org/10.1016/j.precamres.2013.03.008

Ludwig, K. R. (2008). Isoplot/Ex 3.70. A Geochronological Toolkit for Microsoft Excel. Berkeley: Berkeley Geochronological Center, Berkeley. Special publication No. 4., 76p.
Machado, M. M. M., Renger, F. E., Ruchkys, U. A. (2010). Estruturas dobradas do Quadrilátero Ferrífero em Perfis Geológicos do século XIX. Geonomos, 18(2), 73-77. https:// doi.org/10.18285/geonomos.v18i2.74

Machado, N., Carneiro, M. A. (1992). U-Pb evidence of late Archean tectono-thermal activity in the southern São Francisco shield, Brazil. Canadian Journal of Earth Science, 29(11), 2341-2346. https://doi.org/10.1139/e92-182

Machado, N., Noce, C. M., Ladeira, E. A., Belo de Oliveira, O. A. (1992). U-Pb geochronology of Archean magmatism and Proterozoic metamorphism in the Quadrilátero Ferrífero, southern São Francisco craton, Brazil. Geological Society of America Bulletin, 104(9), 1221-1227. https://doi. org/10.1130/0016-7606(1992)104<1221:UPGOAM>2.3.CO;2

Machado, N., Schrank, A. Noce, C. M., Gauthier, G. (1996). Ages of detrital zircon from Archean-Paleoproterozoic sequences: implications for greenstone belt setting and evolution of a transamazonian foreland basin in Quadrilátero Ferrífero, Southeast Brazil. Earth and Planetary Science Letters, 141(1-4), 259-276. https://doi.org/10.1016/0012-821X(96)00054-4

Martínez-Dopico, C. I. M., Lana, C., Moreira, H. S., Cassino, L. F., Alkmim, F. F. (2017). U-Pb ages and Hf-isotope data of detrital zircons from the late Neoarchean-Paleoproterozoic Minas Basin, SE Brazil. Precambrian Research, 291, 143-161. https://doi.org/10.1016/j.precamres.2017.01.026

Maxwell, C. H. (1972). Geology and ore deposits of the Alegria district, Brazil. Washington, USGS/DNPM. Professional Paper 341J. 72p. https://doi.org/10.3133/pp341J

Moreira, H., Lana, C., Nalini Jr., H. A., (2016). The detrital zircon record of an Archaean convergent basin in the Southern São Francisco Craton, Brazil. Precambrian Research, 275, 84-99. https://doi.org/10.1016/j.precamres.2015.12.015

Noce, C. M., Pedrosa-Soares, A. C., Silva, L. C., Armstrong, R., Piuzana, D. (2007). Evolution of polycyclic basement complexes in the Araçuaí orogen, based on U-Pb SHRIMP data: Implication of Brazil-Africa links in Paleoproterozoic time. Precambrian Research, 159(1-2), 60-78. https://doi. org/10.1016/j.precamres.2007.06.001

Noce, C. M., Zucchetti, M., Baltazar, O. F., Armstrong, R., Dantas, E. L., Renger, F. E., Lobato, L. M. (2005). Age of felsic volcanism and the role of ancient continental crust in the evolution of the Neoarchean Rio das Velhas greenstone belt (Quadrilátero Ferrífero, Brazil): U-Pb zircon dating of volcaniclastic graywackes. Precambrian Research, 141(1-2), 67-82. https://doi.org/10.1016/j.precamres.2005.08.002 
Pissis, A. (1848). Mémoire sur la position géologique des terrains de la partie australe du Brésil, et sur les soulèvements qui, à diverses époques, ont changé le relief de cette contrée. Paris: Académie des Sciences de L'Institut National de France, Memoires t. X , p. 353-413.

Ribeiro, F. M., Alkmim, F. F. (1997). O sistema de falhas de empurrão do Sinclinal de Dom Bosco, porção sul do Quadrilátero Ferrífero (MG), em modelagens físicas 3D. Simpósio de Geologia de Minas Gerais, 9. Anais... Ouro Preto: SBG - Núcleo MG-Bol. 14, 74-76.

Rolim, V. K., Alkmim, F. F. (2004). Geometria 3D de falhas de empurrão e dobras associadas como expressões da morfologia do descolamento basal: Resultados de uma simulação computacional. Revista Brasileira de Geociências, 34(3), 295-302. https://doi.org/10.25249/0375-7536.2004343295302

Romano, R., Lana, C., Alkmim, F. F., Stevens, G. S., Armstrong, R. (2013). Stabilization of the southern portion of the São Francisco Craton, SE Brazil, through a long-lived period of potassic magmatism. Precambrian Research, 224, 143-159. https://doi.org/10.1016/j.precamres.2012.09.002

Seixas, L. A. R., Bardintzeff, J.-M., Stevenson, R., Bonin, B. (2013). Petrology of the high- Mg tonalites and dioritic enclaves of the ca. 2130 Ma Alto Maranhão suite: evidence for a major juvenile crustal addition event during the Rhyacian orogenesis, Mineiro Belt, southeast Brazil. Precambrian Research, 238, 18-41. https://doi.org/10.1016/j. precamres.2013.09.015

Seixas, L. A. R., David, J., Stevenson, R. (2012). Geochemistry, $\mathrm{Nd}$ isotopes and $\mathrm{U}-\mathrm{Pb}$ geochronology of a 2350 Ma TTG suite, Minas Gerais Brazil: implications for the crustal evolution of the southern São Francisco craton. Precambrian Research, 196-197, 61-80. https://doi. org/10.1016/j.precamres.2011.11.002

Silva, A. M., Chemale Jr., F., Kuyumjian, R. M., Heaman, L. (1995). Mafic dike swarms of Quadrilátero Ferrífero and Southern Espinhaço, Minas Gerais, Brazil. Revista
Brasileira de Geociencias, 25(2), 124-137. https://doi. org/10.25249/0375-7536.1995124137

Silva, L. C., Pedrosa-Soares, A. C., Armstrong, R., Pinto, C. P., Magalhães, J. T. R., Pinheiro, M. A. P., Santos, G. G. (2016). Disclosing the Paleoarchean to Ediacaran history of the Sao Francisco craton basement: The Porteirinha domain (northern Araçuaí orogen, Brazil). Journal of South American Earth Sciences, 68, 50-67. https://doi.org/10.1016/j. jsames.2015.12.002

Takenaka, L. B. O. (2013). Otimização da Metodologia de Datação U-Pb por Espectrometria de Massa com Ablação a Laser (LA-Q-ICP-MS). Trabalho de Conclusão de Curso. Ouro Preto: Universidade Federal de Ouro Preto, $37 \mathrm{p}$.

Teixeira, W., Ávila, C. A., Dussin, I. A., Corrêa Neto, A. V., Bongiolo, E. M., Santos, J. O. S., Barbosa, N. S. (2015). A juvenile accretion episode (2.35-2.32 Ga) in the Mineiro belt and its role to the Minas accretionary orogeny: Zircon U-Pb-Hf and geochemical evidences. Precambrian Research, 256, 148-169. https://doi.org/10.1016/j.precamres.2014.11.009

Teixeira, W., Carneiro, M. A., Noce, C. M., Machado, N., Sato, K., Taylor, P. N. (1996). Pb, Sr and Nd isotope constraints on the Archaean evolution of gneissic-granitoid complexes in the southern São Francisco Craton, Brazil. Precambrian Research, 78(1-3), 151-164. https://doi. org/10.1016/0301-9268(95)00075-5

Tessari Filho, O., Amorim, L. Q. (1984). Evolução Sedimentar e Tectônica do Grupo Itacolomi na Região de Passagem de Mariana. Revista Escola de Minas, 37(4), 31-44.

Van Achterbergh, E., Ryan, C. G., Jackson, S. E., Griffin, W. L. (2001). Data reduction software for LA-ICP-MS: appendix. Assoc. Canada (MAC) Short Course Series, 29, 239.

Wallace, R. M. (1965). Geology and mineral resources of Pico de Itabirito District, Minas Gerais, Brazil. US Geol. Surv. 68p. (Profissional Paper. 341-F). https://doi. org/10.3133/pp341F 
Apêndice 1. Amostra TR 310 (UTM: 659741 / 7740173).

\begin{tabular}{|c|c|c|c|c|c|c|c|c|c|c|c|}
\hline $\begin{array}{c}I \\
206 / 238\end{array}$ & $1 \sigma$ & $\begin{array}{c}\text { I } \\
207 / 235\end{array}$ & $1 \sigma$ & Conc. & ${ }^{*} \mathrm{RHO}$ & $\begin{array}{c}\text { I } \\
206 / 238\end{array}$ & $1 \sigma$ & $\begin{array}{c}\text { I } \\
207 / 235\end{array}$ & $1 \sigma$ & Conc. & ${ }^{*} \mathrm{RHO}$ \\
\hline $3.405,30$ & 28,86 & $3.348,30$ & 10,69 & 1,02 & 1,00 & $2.414,40$ & 23,09 & $2.550,60$ & 12,18 & 0,95 & 0,88 \\
\hline $3.052,20$ & 26,79 & $3.063,20$ & 10,67 & 1,00 & 1,00 & $2.345,10$ & 23,28 & $2.320,90$ & 11,23 & 1,01 & 0,96 \\
\hline $2.780,40$ & 24,48 & $2.768,80$ & 10,34 & 1,00 & 1,00 & $2.336,50$ & 21,87 & $2.311,50$ & 10,67 & 1,01 & 0,95 \\
\hline $2.742,40$ & 25,75 & $2.729,80$ & 10,96 & 1,00 & 0,99 & $2.314,90$ & 20,43 & $2.312,30$ & 10,07 & 1,00 & 0,95 \\
\hline $2.894,50$ & 25,19 & $2.830,60$ & 10,36 & 1,02 & 0,99 & $2.319,90$ & 21,22 & $2.318,60$ & 10,47 & 1,00 & 0,95 \\
\hline $2.184,90$ & 20,44 & $2.435,70$ & 10,28 & 0,90 & 0,99 & $2.322,20$ & 20,71 & $2.315,20$ & 10,22 & 1,00 & 0,95 \\
\hline $2.729,60$ & 24,59 & $2.731,90$ & 10,57 & 1,00 & 0,99 & $2.326,80$ & 22,15 & $2.325,10$ & 11,13 & 1,00 & 0,93 \\
\hline $3.065,30$ & 26,32 & $3.074,70$ & 10,53 & 1,00 & 0,99 & $2.331,40$ & 26,66 & $2.321,70$ & 13,82 & 1,00 & 0,90 \\
\hline $3.045,00$ & 27,29 & $3.027,70$ & 10,95 & 1,01 & 0,99 & $1.810,50$ & 17,14 & $2.185,50$ & 9,88 & 0,83 & 0,99 \\
\hline $2.246,30$ & 19,70 & $2.735,00$ & 9,94 & 0,82 & 0,99 & $2.218,40$ & 20,50 & $2.217,10$ & 10,05 & 1,00 & 0,98 \\
\hline $1.984,20$ & 18,39 & $2.328,50$ & 9,94 & 0,85 & 0,99 & $2.020,70$ & 20,98 & $2.286,90$ & 11,20 & 0,88 & 0,98 \\
\hline $2.657,70$ & 22,80 & $2.770,40$ & 10,05 & 0,96 & 0,99 & $2.232,70$ & 21,03 & $2.215,70$ & 10,31 & 1,01 & 0,97 \\
\hline $2.142,40$ & 20,24 & $2.481,40$ & 10,43 & 0,86 & 0,99 & $2.190,70$ & 19,10 & $2.239,50$ & 9,59 & 0,98 & 0,97 \\
\hline $3.086,70$ & 27,44 & $3.063,40$ & 10,94 & 1,01 & 0,99 & $2.211,70$ & 20,68 & $2.209,60$ & 10,39 & 1,00 & 0,96 \\
\hline $2.673,50$ & 23,96 & $2.684,30$ & 10,50 & 1,00 & 0,98 & $1.774,70$ & 18,69 & $2.210,10$ & 11,48 & 0,80 & 0,95 \\
\hline $2.905,50$ & 24,87 & $2.910,20$ & 10,35 & 1,00 & 0,98 & $2.229,30$ & 20,06 & $2.214,50$ & 10,28 & 1,01 & 0,93 \\
\hline $3.213,60$ & 26,77 & $3.236,30$ & 10,50 & 0,99 & 0,98 & $2.211,60$ & 19,41 & $2.207,70$ & 10,22 & 1,00 & 0,91 \\
\hline $2.660,70$ & 25,27 & $2.685,70$ & 11,14 & 0,99 & 0,98 & $2.187,00$ & 20,29 & $2.209,10$ & 10,85 & 0,99 & 0,91 \\
\hline $3.039,10$ & 25,51 & $3.061,10$ & 10,36 & 0,99 & 0,98 & $2.210,70$ & 20,36 & $2.214,30$ & 10,85 & 1,00 & 0,90 \\
\hline $2.781,50$ & 23,66 & $2.773,50$ & 10,14 & 1,00 & 0,98 & $2.190,70$ & 23,92 & $2.209,10$ & 13,49 & 0,99 & 0,86 \\
\hline $2.939,30$ & 27,54 & $2.989,90$ & 11,47 & 0,98 & 0,98 & $1.533,30$ & 16,23 & $2.043,70$ & 10,71 & 0,75 & 0,98 \\
\hline $2.307,40$ & 23,17 & $2.660,70$ & 11,51 & 0,87 & 0,98 & $2.081,70$ & 19,55 & $2.118,30$ & 10,06 & 0,98 & 0,97 \\
\hline $2.733,50$ & 24,43 & $2.732,30$ & 10,63 & 1,00 & 0,98 & $2.169,40$ & 21,31 & $2.148,60$ & 10,68 & 1,01 & 0,97 \\
\hline $3.023,30$ & 25,14 & $3.002,70$ & 10,28 & 1,01 & 0,98 & $1.761,70$ & 17,32 & $2.088,60$ & 10,35 & 0,84 & 0,96 \\
\hline $2.637,70$ & 25,59 & $2.862,50$ & 11,59 & 0,92 & 0,97 & $2.006,50$ & 20,08 & $2.090,20$ & 10,92 & 0,96 & 0,94 \\
\hline $2.676,50$ & 25,20 & $2.685,50$ & 11,17 & 1,00 & 0,97 & $2.067,00$ & 19,83 & $2.113,00$ & 10,67 & 0,98 & 0,93 \\
\hline $3.064,30$ & 25,24 & $3.064,10$ & 10,30 & 1,00 & 0,97 & $1.923,50$ & 20,29 & $2.008,10$ & 11,46 & 0,96 & 0,93 \\
\hline $2.441,20$ & 22,71 & $2.915,60$ & 11,05 & 0,84 & 0,97 & $1.936,40$ & 19,97 & $2.054,70$ & 11,30 & 0,94 & 0,93 \\
\hline $3.206,40$ & 29,97 & $3.094,90$ & 11,88 & 1,04 & 0,97 & $2.166,50$ & 19,34 & $2.156,60$ & 10,10 & 1,00 & 0,93 \\
\hline $2.681,30$ & 27,42 & $2.684,70$ & 12,23 & 1,00 & 0,96 & $2.201,60$ & 20,14 & $2.153,00$ & 10,45 & 1,02 & 0,92 \\
\hline $2.927,40$ & 26,47 & $2.927,00$ & 11,22 & 1,00 & 0,96 & $2.140,10$ & 18,74 & $2.151,50$ & 9,98 & 0,99 & 0,92 \\
\hline $2.840,00$ & 24,68 & $2.874,80$ & 10,70 & 0,99 & 0,96 & $1.925,20$ & 18,86 & $2.031,20$ & 10,88 & 0,95 & 0,91 \\
\hline $3.037,00$ & 27,49 & $3.075,70$ & 11,52 & 0,99 & 0,95 & $2.149,10$ & 19,74 & $2.152,10$ & 10,57 & 1,00 & 0,91 \\
\hline $3.036,90$ & 29,47 & $3.021,20$ & 12,33 & 1,01 & 0,95 & $2.047,70$ & 20,44 & $2.104,50$ & 11,38 & 0,97 & 0,91 \\
\hline $3.061,10$ & 24,65 & $3.077,00$ & 10,36 & 0,99 & 0,94 & $2.091,50$ & 19,38 & $2.090,20$ & 10,91 & 1,00 & 0,88 \\
\hline $2.922,40$ & 26,67 & $2.893,10$ & 11,55 & 1,01 & 0,94 & $2.128,80$ & 21,27 & $2.146,70$ & 12,16 & 0,99 & 0,86 \\
\hline $3.051,00$ & 27,16 & $3.054,70$ & 11,48 & 1,00 & 0,94 & $2.163,30$ & 22,47 & $2.156,60$ & 12,80 & 1,00 & 0,85 \\
\hline $1.930,50$ & 20,19 & $2.546,00$ & 12,33 & 0,76 & 0,92 & $2.158,60$ & 23,58 & $2.159,50$ & 13,85 & 1,00 & 0,83 \\
\hline $2.670,10$ & 26,34 & $2.643,50$ & 12,38 & 1,01 & 0,91 & $2.174,20$ & 22,54 & $2.155,20$ & 13,63 & 1,01 & 0,80 \\
\hline $2.815,30$ & 38,40 & $2.902,30$ & 17,76 & 0,97 & 0,91 & & & & & & \\
\hline
\end{tabular}

| 206/238: idades ${ }^{206} \mathrm{~Pb} / 238 \mathrm{U}$, em milhões de anos; I 207/235: idades ${ }^{207} \mathrm{~Pb} / 235 \mathrm{U}$, em milhões de anos; Conc.: concordância; *RHO: correlação de erro definida como o quociente da propagação de erros das razões ${ }^{206} \mathrm{~Pb} / 238 \mathrm{U}$ e ${ }^{207} \mathrm{~Pb} /{ }^{235} \mathrm{U}$. 
Apêndice 2. Amostra TR 312 (UTM: 659259 / 7740363)

\begin{tabular}{|c|c|c|c|c|c|c|c|c|c|c|c|}
\hline $\begin{array}{c}\text { I } \\
206 / 238\end{array}$ & $1 \sigma$ & $\begin{array}{c}\text { I } \\
207 / 235\end{array}$ & $1 \sigma$ & Conc. & ${ }^{*} \mathrm{RHO}$ & $\begin{array}{c} \\
206 / 238\end{array}$ & $1 \sigma$ & $\begin{array}{c}\text { I } \\
207 / 235\end{array}$ & $1 \sigma$ & Conc. & ${ }^{*} \mathrm{RHO}$ \\
\hline $3.054,70$ & 31,86 & $3.383,00$ & 13,25 & 0,90 & 0,97 & $2.560,30$ & 29,05 & $2.578,00$ & 13,99 & 0,99 & 0,92 \\
\hline $3.387,50$ & 32,24 & $3.340,10$ & 11,98 & 1,01 & 1,00 & $2.337,00$ & 26,85 & $2.534,10$ & 13,77 & 0,92 & 0,93 \\
\hline $3.378,00$ & 30,65 & $3.339,10$ & 11,41 & 1,01 & 1,00 & $2.207,20$ & 24,21 & $2.456,20$ & 12,36 & 0,90 & 0,97 \\
\hline $3.213,40$ & 32,45 & $3.262,90$ & 13,03 & 0,98 & 0,96 & $2.050,00$ & 22,01 & $2.454,80$ & 11,98 & 0,84 & 0,97 \\
\hline $3.090,70$ & 29,64 & $3.106,40$ & 12,04 & 0,99 & 0,97 & $2.289,50$ & 22,73 & $2.432,90$ & 11,03 & 0,94 & 0,99 \\
\hline $3.101,90$ & 28,47 & $3.095,50$ & 11,40 & 1,00 & 0,98 & $2.149,70$ & 21,96 & $2.414,90$ & 11,74 & 0,89 & 0,94 \\
\hline $3.113,90$ & 29,23 & $3.089,50$ & 11,52 & 1,01 & 0,99 & $1.816,40$ & 18,94 & $2.374,60$ & 11,00 & 0,76 & 1,00 \\
\hline $3.041,00$ & 28,91 & $3.076,40$ & 11,82 & 0,99 & 0,98 & $2.158,20$ & 19,69 & $2.370,90$ & 10,49 & 0,91 & 0,94 \\
\hline $2.708,20$ & 29,21 & $3.050,10$ & 13,22 & 0,89 & 0,96 & $1.943,70$ & 22,67 & $2.350,90$ & 13,74 & 0,83 & 0,90 \\
\hline $3.012,10$ & 27,03 & $2.998,90$ & 11,01 & 1,00 & 0,98 & $2.321,60$ & 23,35 & $2.314,90$ & 11,26 & 1,00 & 0,97 \\
\hline $2.984,10$ & 26,50 & $2.986,10$ & 10,88 & 1,00 & 0,98 & $2.307,30$ & 23,31 & $2.311,40$ & 12,12 & 1,00 & 0,90 \\
\hline $2.864,40$ & 29,17 & $2.977,90$ & 12,94 & 0,96 & 0,94 & $2.308,00$ & 23,33 & $2.310,20$ & 11,50 & 1,00 & 0,95 \\
\hline $2.894,90$ & 27,61 & $2.932,70$ & 11,67 & 0,99 & 0,97 & $1.802,90$ & 19,30 & $2.306,00$ & 11,34 & 0,78 & 0,99 \\
\hline $2.881,30$ & 26,92 & $2.922,00$ & 11,18 & 0,99 & 0,99 & $2.305,90$ & 31,56 & $2.305,50$ & 18,31 & 1,00 & 0,81 \\
\hline $2.855,90$ & 27,03 & $2.883,80$ & 12,18 & 0,99 & 0,92 & $2.085,00$ & 20,31 & $2.285,80$ & 10,61 & 0,91 & 0,98 \\
\hline $2.839,40$ & 28,85 & $2.882,80$ & 12,30 & 0,98 & 0,98 & $2.058,90$ & 20,93 & $2.277,60$ & 11,21 & 0,90 & 0,96 \\
\hline $2.835,20$ & 26,89 & $2.882,10$ & 11,29 & 0,98 & 0,99 & $2.226,30$ & 24,01 & $2.234,50$ & 13,02 & 1,00 & 0,88 \\
\hline $2.869,40$ & 29,32 & $2.881,70$ & 12,30 & 1,00 & 0,98 & $2.223,40$ & & $2.233,60$ & 11,03 & 1,00 & 0,93 \\
\hline $2.876,30$ & 30,11 & $2.880,00$ & 13,01 & 1,00 & 0,95 & $2.225,90$ & 21,18 & $2.230,20$ & 10,26 & 1,00 & 0,99 \\
\hline $2.862,70$ & 29,25 & $2.878,40$ & 12,21 & 0,99 & 0,99 & $2.232,70$ & 20,85 & $2.222,90$ & 10,27 & 1,00 & 0,97 \\
\hline $2.861,40$ & 25,89 & $2.878,00$ & 11,21 & 0,99 & 0,96 & $2.216,90$ & 22,18 & $2.222,30$ & 11,50 & 1,00 & 0,93 \\
\hline $2.835,20$ & 28,60 & $2.825,20$ & 12,31 & 1,00 & 0,96 & $2.179,50$ & 26,33 & $2.221,30$ & 14,95 & 0,98 & 0,86 \\
\hline $2.743,70$ & 29,11 & $2.804,00$ & 13,16 & 0,98 & 0,94 & $1.672,10$ & 16,39 & $2.196,30$ & 10,36 & 0,76 & 0,97 \\
\hline $2.688,90$ & 28,80 & $2.799,40$ & 13,34 & 0,96 & 0,93 & $2.172,50$ & 20,83 & $2.190,40$ & 10,66 & 0,99 & 0,95 \\
\hline $2.616,70$ & 27,50 & $2.795,10$ & 12,58 & 0,94 & 0,97 & $2.189,70$ & 21,07 & $2.187,70$ & 11,02 & 1,00 & 0,92 \\
\hline $2.763,00$ & 29,25 & $2.784,10$ & 13,20 & 0,99 & 0,94 & $2.175,00$ & 21,77 & $2.185,50$ & 11,16 & 1,00 & 0,95 \\
\hline $2.757,70$ & 28,70 & $2.763,20$ & 12,52 & 1,00 & 0,97 & $2.124,00$ & 21,17 & $2.185,10$ & 11,13 & 0,97 & 0,94 \\
\hline $2.757,30$ & 29,80 & $2.757,70$ & 13,23 & 1,00 & 0,95 & $2.162,20$ & 22,13 & $2.184,20$ & 11,00 & 0,99 & 0,98 \\
\hline $2.788,10$ & 28,67 & $2.754,40$ & 12,86 & 1,01 & 0,93 & $2.160,70$ & 21,08 & $2.181,30$ & 10,52 & 0,99 & 0,98 \\
\hline $2.775,20$ & 38,28 & $2.750,90$ & 20,45 & 1,01 & 0,79 & $2.191,40$ & 21,05 & $2.180,10$ & 10,74 & 1,01 & 0,95 \\
\hline $2.763,50$ & 36,87 & $2.739,60$ & 17,58 & 1,01 & 0,88 & $1.664,10$ & 18,31 & $2.179,10$ & 12,00 & 0,76 & 0,93 \\
\hline $2.740,40$ & 27,17 & $2.721,50$ & 11,94 & 1,01 & 0,96 & $2.139,10$ & 27,60 & $2.177,00$ & 16,63 & 0,98 & 0,82 \\
\hline $2.626,80$ & 29,90 & $2.665,90$ & 14,36 & 0,99 & 0,91 & $2.159,90$ & 23,96 & $2.176,20$ & 13,88 & 0,99 & 0,84 \\
\hline $2.633,10$ & 24,60 & $2.657,00$ & 11,05 & 0,99 & 0,97 & $2.156,70$ & 23,29 & $2.174,80$ & 11,52 & 0,99 & 0,99 \\
\hline $2.647,70$ & 30,30 & $2.654,00$ & 14,67 & 1,00 & 0,90 & $2.164,20$ & 22,34 & $2.169,30$ & 12,21 & 1,00 & 0,89 \\
\hline $2.646,10$ & 25,39 & $2.654,00$ & 11,48 & 1,00 & 0,96 & $2.174,40$ & 24,35 & $2.168,20$ & 12,47 & 1,00 & 0,95 \\
\hline $2.594,30$ & 28,63 & $2.615,70$ & 13,25 & 0,99 & 0,95 & $2.190,70$ & 21,50 & $2.135,70$ & 11,36 & 1,03 & 0,91 \\
\hline $2.581,00$ & 26,21 & $2.614,00$ & 11,62 & 0,99 & 1,00 & $2.139,10$ & 20,57 & $2.129,90$ & 10,70 & 1,00 & 0,94 \\
\hline $2.646,70$ & 28,32 & $2.600,40$ & 13,20 & 1,02 & 0,93 & $2.122,20$ & 20,38 & $2.126,10$ & 10,68 & 1,00 & 0,94 \\
\hline $2.572,90$ & 27,24 & $2.597,90$ & 12,95 & 0,99 & 0,93 & $2.110,20$ & 20,60 & $2.121,40$ & 10,73 & 0,99 & 0,95 \\
\hline
\end{tabular}

I 206/238: idades ${ }^{206} \mathrm{~Pb} / 238 \mathrm{U}$, em milhões de anos; I 207/235: idades ${ }^{207} \mathrm{~Pb} / 235 \mathrm{U}$, em milhões de anos; Conc.: concordância; *RHO: correlação de erro definida como o quociente da propagação de erros das razões ${ }^{206} \mathrm{~Pb} / 238 \mathrm{U}$ e ${ }^{207} \mathrm{~Pb} /{ }^{235} \mathrm{U}$. 
Apêndice 3. Amostra TR 314 (UTM: 657356 / 7739832)

\begin{tabular}{|c|c|c|c|c|c|c|c|c|c|c|c|}
\hline $\begin{array}{c}\text { I } \\
206 / 238\end{array}$ & $1 \sigma$ & $\begin{array}{c}\text { I } \\
207 / 235\end{array}$ & $1 \sigma$ & Conc. & ${ }^{*} \mathrm{RHO}$ & $\begin{array}{c}I \\
206 / 238\end{array}$ & $1 \sigma$ & $\begin{array}{c}\text { I } \\
207 / 235\end{array}$ & $1 \sigma$ & Conc. & ${ }^{*} \mathrm{RHO}$ \\
\hline $3.146,70$ & 32,04 & $3.154,70$ & 12,75 & 1,00 & 0,98 & $2.253,70$ & 24,88 & $2.229,10$ & 12,75 & 1,01 & 0,93 \\
\hline $3.156,40$ & 31,59 & $3.057,80$ & 12,49 & 1,03 & 0,98 & $2.218,30$ & 23,67 & $2.228,60$ & 12,11 & 1,00 & 0,94 \\
\hline $3.054,60$ & 41,29 & $2.996,80$ & 17,94 & 1,02 & 0,91 & $2.233,00$ & 24,10 & 2.226,60 & 11,75 & 1,00 & 0,98 \\
\hline $2.928,30$ & 29,42 & $2.920,00$ & 12,40 & 1,00 & 0,97 & $2.240,00$ & 25,05 & $2.226,20$ & 12,76 & 1,01 & 0,94 \\
\hline $2.900,60$ & 35,70 & $2.910,10$ & 15,90 & 1,00 & 0,92 & $2.246,90$ & 25,46 & $2.223,10$ & 12,95 & 1,01 & 0,94 \\
\hline $2.905,90$ & 29,27 & $2.905,10$ & 12,47 & 1,00 & 0,96 & $2.227,40$ & 23,86 & $2.217,70$ & 12,17 & 1,00 & 0,94 \\
\hline $2.846,50$ & 35,87 & $2.849,00$ & 15,61 & 1,00 & 0,95 & $2.229,90$ & 24,83 & $2.217,40$ & 11,96 & 1,01 & 0,99 \\
\hline $2.692,60$ & 29,90 & 2.826,20 & 13,30 & 0,95 & 0,97 & $2.235,60$ & 23,76 & $2.211,70$ & 11,96 & 1,01 & 0,95 \\
\hline $2.618,20$ & 28,46 & $2.819,10$ & 13,03 & 0,93 & 0,97 & $2.189,50$ & 23,96 & $2.208,60$ & 12,68 & 0,99 & 0,92 \\
\hline $2.766,80$ & 33,75 & $2.778,40$ & 15,34 & 1,00 & 0,93 & $2.230,40$ & 25,65 & $2.182,30$ & 13,16 & 1,02 & 0,93 \\
\hline $2.650,70$ & 28,89 & $2.646,50$ & 13,39 & 1,00 & 0,93 & $2.194,00$ & 24,47 & $2.179,10$ & 12,20 & 1,01 & 0,97 \\
\hline $2.642,10$ & 28,65 & $2.644,70$ & 12,64 & 1,00 & 0,98 & $2.190,40$ & & $2.178,20$ & & 1,01 & 0,86 \\
\hline $1.989,80$ & 22,15 & $2.510,40$ & 12,12 & 0,79 & 0,99 & $2.205,70$ & 24,07 & $2.177,70$ & 12,18 & 1,01 & 0,95 \\
\hline $2.340,00$ & 25,74 & $2.496,30$ & 12,31 & 0,94 & 0,99 & $2.152,50$ & 24,86 & $2.171,70$ & 12,49 & 0,99 & 0,98 \\
\hline $2.453,90$ & 32,47 & $2.433,40$ & 16,03 & 1,01 & 0,92 & $2.164,90$ & 24,18 & $2.170,20$ & 12,30 & 1,00 & 0,96 \\
\hline $2.073,60$ & 25,24 & $2.416,20$ & 13,43 & 0,86 & 0,98 & $2.155,20$ & 23,12 & $2.169,10$ & 11,95 & 0,99 & 0,95 \\
\hline $1.927,80$ & 23,14 & $2.406,70$ & 13,43 & 0,80 & 0,95 & $2.193,50$ & 24,37 & $2.167,40$ & & 1 & 0,97 \\
\hline $2.372,30$ & 28,73 & $2.394,50$ & 14,14 & 0,99 & 0,94 & $2.188,20$ & 23,27 & $2.164,00$ & 11,89 & 1,01 & 0,94 \\
\hline $1.776,00$ & 20,13 & $2.342,00$ & 12,00 & 0,76 & 0,99 & $2.203,60$ & 23,47 & $2.163,90$ & 12,03 & 1,02 & 0,94 \\
\hline $2.246,20$ & 23,66 & $2.327,30$ & 11,72 & 0,97 & 0,97 & $2.153,10$ & 24,50 & $2.155,20$ & 12,68 & 1,00 & 0,94 \\
\hline $2.324,30$ & 26,28 & $2.303,20$ & 13,37 & 1,01 & 0,92 & $1.361,30$ & 15,35 & $2.154,70$ & 11,87 & 0,63 & 0,94 \\
\hline $2.306,40$ & 25,50 & $2.302,80$ & 12,26 & 1,00 & 0,98 & $2.122,00$ & 23,48 & $2.151,70$ & 13,24 & 0,99 & 0,88 \\
\hline $1.294,90$ & 14,97 & $2.277,10$ & 11,71 & 0,57 & 0,99 & $2.142,30$ & 23,79 & $2.149,80$ & 12,44 & 1,00 & 0,94 \\
\hline $1.947,90$ & 21,75 & $2.260,40$ & 12,35 & 0,86 & 0,95 & $2.073,70$ & 26,71 & $2.149,20$ & 14,62 & 0,96 & 0,92 \\
\hline $2.235,50$ & 25,02 & $2.256,90$ & 12,95 & 0,99 & 0,93 & $2.123,10$ & 23,31 & $2.149,10$ & 12,79 & 0,99 & 0,90 \\
\hline $2.196,40$ & 24,42 & $2.248,10$ & 12,92 & 0,98 & 0,92 & $1.408,50$ & 17,26 & $2.147,30$ & 12,18 & 0,66 & 1,00 \\
\hline $2.248,50$ & 28,31 & $2.242,00$ & 15,06 & 1,00 & 0,89 & $2.120,40$ & 25,04 & $2.146,10$ & 13,80 & 0,99 & 0,90 \\
\hline $2.252,50$ & 24,43 & $2.234,50$ & 12,26 & 1,01 & 0,95 & $2.162,20$ & 23,62 & $2.144,50$ & 11,96 & 1,01 & 0,96 \\
\hline $2.248,90$ & 25,27 & $2.229,40$ & 12,42 & 1,01 & 0,97 & & & & & & \\
\hline
\end{tabular}

I 206/238: idades ${ }^{206} \mathrm{~Pb} /{ }^{238} \mathrm{U}$, em milhões de anos; I 207/235: idades ${ }^{207} \mathrm{~Pb} /{ }^{235} \mathrm{U}$, em milhões de anos; Conc.: concordância; *RHO: correlação de erro definida como o quociente da propagação de erros das razões ${ }^{206} \mathrm{~Pb} /{ }^{238} \mathrm{U}$ e ${ }^{207} \mathrm{~Pb} / 235 \mathrm{U}$. 
Apêndice 4. Amostra TR 315 (UTM: 657268 / 7739775).

\begin{tabular}{|c|c|c|c|c|c|c|c|c|c|c|c|}
\hline $\begin{array}{c}\text { I } \\
206 / 238 \\
\end{array}$ & $1 \sigma$ & $\begin{array}{c}\text { I } \\
207 / 235 \\
\end{array}$ & $1 \sigma$ & Conc. & ${ }^{*} \mathrm{RHO}$ & $\begin{array}{c}\text { I } \\
206 / 238 \\
\end{array}$ & $1 \sigma$ & $\begin{array}{c}\text { I } \\
207 / 235 \\
\end{array}$ & $1 \sigma$ & Conc. & ${ }^{*} \mathrm{RHO}$ \\
\hline $7.222,10$ & 57,09 & $5.472,30$ & 14,01 & 1,32 & 0,95 & $1.852,20$ & 19,58 & $2.249,20$ & 11,55 & 0,82 & 0,95 \\
\hline $2.487,10$ & 27,59 & $3.947,00$ & 13,67 & 0,63 & 0,97 & $1.405,90$ & 16,98 & $2.244,40$ & 12,79 & 0,63 & 0,95 \\
\hline $3.157,50$ & 34,89 & $3.194,40$ & 14,08 & 0,99 & 0,96 & $2.231,10$ & 26,27 & $2.227,10$ & 13,10 & 1,00 & 0,96 \\
\hline $3.107,30$ & 31,41 & $3.193,40$ & 12,66 & 0,97 & 0,98 & $2.198,10$ & 25,58 & $2.224,50$ & 13,11 & 0,99 & 0,94 \\
\hline $3.196,50$ & 31,80 & $3.186,80$ & 13,27 & 1,00 & 0,92 & $2.234,00$ & 24,07 & $2.217,60$ & 12,64 & 1,01 & 0,91 \\
\hline $3.141,40$ & 31,11 & $3.186,70$ & 12,36 & 0,99 & 0,98 & $2.218,30$ & 23,80 & $2.217,60$ & 11,82 & 1,00 & 0,97 \\
\hline $3.158,00$ & 35,77 & $3.183,50$ & 14,19 & 0,99 & 0,98 & $2.212,90$ & 22,80 & $2.213,80$ & 11,76 & 1,00 & 0,93 \\
\hline $3.047,60$ & 30,76 & $3.088,90$ & 12,33 & 0,99 & 0,99 & $2.206,40$ & 23,39 & $2.213,40$ & 11,98 & 1,00 & 0,94 \\
\hline $2.517,60$ & 29,23 & $3.078,20$ & 13,75 & 0,82 & 0,99 & $2.234,10$ & 24,85 & $2.210,20$ & 12,56 & 1,01 & 0,94 \\
\hline $3.065,20$ & 31,30 & $3.044,30$ & 12,79 & 1,01 & 0,97 & $2.225,70$ & 23,69 & $2.209,60$ & 11,83 & 1,01 & 0,96 \\
\hline $3.066,40$ & 29,91 & $3.041,30$ & 12,23 & 1,01 & 0,97 & $2.175,10$ & 24,56 & $2.209,30$ & 12,55 & 0,98 & 0,95 \\
\hline $2.407,10$ & 24,23 & $3.000,60$ & 11,97 & 0,80 & 0,97 & $2.182,80$ & 26,90 & $2.209,10$ & 14,01 & 0,99 & 0,93 \\
\hline $2.946,00$ & 32,28 & $2.922,40$ & 13,34 & 1,01 & 0,98 & $2.227,20$ & 22,83 & $2.208,00$ & 11,45 & 1,01 & 0,95 \\
\hline $2.911,90$ & 29,45 & $2.913,20$ & 12,86 & 1,00 & 0, & $2.182,60$ & 24,49 & $2.207,40$ & 12,83 & 0,99 & 0,93 \\
\hline $2.918,70$ & 31,59 & $2.911,30$ & 13,93 & 1,0 & 0 & $2.212,80$ & 23,68 & $2.206,60$ & 11,73 & 1,00 & 0,97 \\
\hline $2.501,20$ & 25,52 & $2.907,20$ & 12,99 & 0,86 & 0,91 & $2.206,00$ & 23,14 & $2.204,60$ & 11,50 & 1,00 & 0,97 \\
\hline $2.868,60$ & 29,34 & $2.898,80$ & 12,47 & 0,99 & 0,97 & $2.166,90$ & 23,83 & $2.167,90$ & 12,08 & 1,00 & 0,96 \\
\hline $2.736,00$ & 29,01 & $2.807,50$ & 13,57 & 0,97 & 0,91 & $2.145,20$ & 22,84 & $2.163,20$ & 11,77 & 0,99 & 0,95 \\
\hline $2.760,40$ & 31,24 & $2.801,50$ & 14,21 & 0,99 & 0,93 & $2.154,20$ & 23,02 & $2.162,60$ & 12,00 & 1,00 & 0,94 \\
\hline $2.790,50$ & 29,76 & $2.797,70$ & 13,43 & 1,00 & 0,93 & $2.109,50$ & 21,72 & $2.126,40$ & 11,31 & 0,99 & 0,95 \\
\hline $2.831,80$ & 28,84 & $2.795,80$ & 12,36 & 1,01 & 0,97 & $2.117,00$ & 22,44 & $2.125,30$ & 11,73 & 1,00 & 0,94 \\
\hline $2.545,10$ & 26,13 & $2.691,00$ & 12,69 & 0,95 & 0,92 & $2.111,40$ & 28,45 & $2.120,90$ & 15,40 & 1,00 & 0,91 \\
\hline $1.996,80$ & 21,24 & $2.589,90$ & 12,02 & 0,77 & 0,96 & $2.092,10$ & 23,03 & $2.120,00$ & 12,05 & 0,99 & 0,95 \\
\hline $2.232,50$ & 24,28 & $2.447,10$ & 12,32 & 0,91 & 0,97 & $2.078,50$ & 24,31 & $2.113,40$ & 12,89 & 0,98 & 0,94 \\
\hline $2.390,00$ & 25,94 & $2.381,10$ & 12,19 & 1,00 & 0,98 & $2.066,70$ & 24,49 & $2.109,40$ & 12,72 & 0,98 & 0,97 \\
\hline $2.358,40$ & 27,57 & $2.379,10$ & 14,23 & 0,99 & 0,90 & $2.020,70$ & 22,15 & $2.100,90$ & 11,82 & 0,96 & 0,96 \\
\hline $1.983,40$ & 24,86 & $2.315,30$ & 13,88 & 0,86 & 0,96 & & & & & & \\
\hline
\end{tabular}

| 206/238: idades ${ }^{206} \mathrm{~Pb} /{ }^{238} \mathrm{U}$, em milhões de anos; I 207/235: idades ${ }^{207} \mathrm{~Pb} / 235 \mathrm{U}$, em milhões de anos; Conc.: concordância; *RHO: correlação de erro definida como o quociente da propagação de erros das razões ${ }^{206} \mathrm{~Pb} / 238 \mathrm{U}$ e ${ }^{207} \mathrm{~Pb} /{ }^{235} \mathrm{U}$. 
Apêndice 5. Amostra TR 316 (UTM: 657013 / 7740010).

\begin{tabular}{|c|c|c|c|c|c|c|c|c|c|c|c|}
\hline $\begin{array}{c}I \\
206 / 238\end{array}$ & $1 \sigma$ & $\begin{array}{c}\text { I } \\
207 / 235\end{array}$ & $1 \sigma$ & Conc. & ${ }^{*} \mathrm{RHO}$ & $\begin{array}{c}\text { I } \\
206 / 238\end{array}$ & $1 \sigma$ & $\begin{array}{c}\text { I } \\
207 / 235\end{array}$ & $1 \sigma$ & Conc. & ${ }^{*} \mathrm{RHO}$ \\
\hline $3.378,40$ & 36,82 & $3.383,20$ & 13,63 & 1,00 & 1,01 & $2.267,70$ & 27,84 & $2.246,20$ & 13,75 & 1,01 & 0,96 \\
\hline $3.200,70$ & 31,64 & $3.204,20$ & 12,29 & 1,00 & 0,99 & $2.231,50$ & 25,07 & $2.245,70$ & 12,35 & 0,99 & 0,97 \\
\hline $3.200,90$ & 32,30 & $3.150,10$ & 12,49 & 1,02 & 0,99 & $2.265,10$ & 24,38 & $2.245,00$ & 11,95 & 1,01 & 0,96 \\
\hline $3.204,10$ & 36,83 & $3.103,00$ & 14,68 & 1,03 & 0,96 & $2.275,90$ & 23,89 & $2.245,00$ & 11,69 & 1,01 & 0,96 \\
\hline $2.482,60$ & 26,80 & $3.012,40$ & 12,53 & 0,82 & 1,00 & $2.248,90$ & 25,33 & $2.244,60$ & 12,50 & 1,00 & 0,97 \\
\hline $2.918,40$ & 32,18 & $2.946,30$ & 13,26 & 0,99 & 0,99 & $2.225,10$ & 24,41 & $2.244,60$ & 12,36 & 0,99 & 0,95 \\
\hline $2.929,10$ & 28,74 & $2.936,10$ & 12,12 & 1,00 & 0,97 & $2.216,40$ & 26,70 & $2.242,50$ & 13,28 & 0,99 & 0,97 \\
\hline $2.952,30$ & 30,62 & $2.934,60$ & 12,66 & 1,01 & 0,98 & $2.239,50$ & 24,63 & $2.238,60$ & 12,55 & 1,00 & 0,94 \\
\hline $2.933,30$ & 28,62 & $2.934,00$ & 12,32 & 1,00 & 0,95 & $2.239,90$ & 24,08 & $2.237,90$ & 11,88 & 1,00 & 0,97 \\
\hline $2.960,00$ & 31,65 & $2.933,70$ & 13,71 & 1,01 & 0,93 & $2.215,10$ & 24,27 & $2.195,20$ & 12,46 & 1,01 & 0,93 \\
\hline $2.914,10$ & 29,72 & $2.933,30$ & 12,29 & 0,99 & 0,99 & $2.208,80$ & 24,55 & $2.183,10$ & 12,20 & 1,01 & 0,96 \\
\hline $2.928,00$ & 30,55 & $2.930,60$ & 12,74 & 1,00 & 0,98 & $2.184,70$ & 24,40 & $2.182,10$ & 12,39 & 1,00 & 0,95 \\
\hline $2.867,40$ & 30,34 & $2.862,60$ & 12,74 & 1,00 & 0,98 & $2.202,30$ & 24,86 & $2.181,90$ & 12,24 & 1,01 & 0,98 \\
\hline $2.847,60$ & 33,98 & $2.813,30$ & 14,61 & 1,01 & 0,96 & $2.173,20$ & 24,81 & $2.180,80$ & 12,95 & 1,00 & 0,93 \\
\hline $2.829,70$ & 33,80 & $2.812,60$ & 14,53 & 1,01 & 0,97 & $2.188,80$ & 23,61 & $2.176,50$ & 11,71 & 1,01 & 0,97 \\
\hline $2.813,80$ & 33,19 & $2.810,70$ & 14,53 & 1,00 & 0,95 & $2.174,30$ & 23,43 & $2.174,80$ & 11,59 & 1,00 & 0,98 \\
\hline $2.800,80$ & 32,30 & $2.809,50$ & 14,29 & 1,00 & 0,95 & $2.150,70$ & 23,86 & $2.174,80$ & 12,37 & 0,99 & 0,95 \\
\hline $2.775,70$ & 33,02 & $2.809,30$ & 14,10 & 0,99 & 0,99 & $2.171,20$ & & $2.173,50$ & 12,34 & 1,00 & 0,98 \\
\hline $2.719,20$ & 31,33 & $2.795,20$ & 13,91 & 0,97 & 0,96 & $2.183,00$ & 24,19 & $2.171,50$ & 12,40 & 1,01 & 0,94 \\
\hline $2.490,70$ & 28,00 & $2.783,20$ & 13,45 & 0,89 & 0,96 & $2.162,40$ & 23,62 & $2.168,20$ & 12,03 & 1,00 & 0,96 \\
\hline $2.791,10$ & 30,42 & $2.774,50$ & 13,37 & 1,01 & 0,95 & $2.162,20$ & 25,06 & $2.167,10$ & 12,69 & 1,00 & 0,96 \\
\hline $2.777,60$ & 29,12 & $2.772,90$ & 12,55 & 1,00 & 0,98 & $2.146,20$ & 24,97 & $2.165,40$ & 12,90 & 0,99 & 0,95 \\
\hline $2.783,40$ & 30,59 & $2.743,20$ & 13,36 & 1,01 & 0,96 & $2.164,90$ & 23,66 & $2.165,00$ & 11,74 & 1,00 & 0,98 \\
\hline $2.752,60$ & 29,93 & $2.742,90$ & 13,51 & 1,00 & 0,94 & $2.172,10$ & 23,93 & $2.163,80$ & 11,92 & 1,00 & 0,97 \\
\hline $2.743,10$ & 31,43 & $2.740,50$ & 13,96 & 1,00 & 0,95 & $2.162,90$ & 23,88 & $2.163,80$ & 11,79 & 1,00 & 0,99 \\
\hline $2.760,00$ & 31,39 & $2.739,40$ & 14,26 & 1,01 & 0,93 & $2.162,00$ & 23,59 & $2.160,90$ & 12,03 & 1,00 & 0,96 \\
\hline $2.155,10$ & 26,90 & $2.699,80$ & 14,95 & 0,80 & 0,93 & $2.127,10$ & 22,75 & $2.152,50$ & 11,50 & 0,99 & 0,98 \\
\hline $2.143,50$ & 25,71 & $2.685,90$ & 13,26 & 0,80 & 1,00 & $2.065,90$ & 24,00 & $2.111,70$ & 12,77 & 0,98 & 0,94 \\
\hline $2.204,80$ & 24,81 & $2.510,80$ & 12,43 & 0,88 & 0,99 & $1.966,10$ & 23,17 & $2.109,90$ & 12,86 & 0,93 & 0,95 \\
\hline $2.376,70$ & 29,73 & $2.374,90$ & 14,64 & 1,00 & 0,94 & $2.023,20$ & 22,51 & $2.071,00$ & 12,16 & 0,98 & 0,94 \\
\hline $2.265,90$ & 25,98 & $2.288,30$ & 12,82 & 0,99 & 0,96 & $1.986,50$ & 21,15 & $2.058,50$ & 11,56 & 0,97 & 0,94 \\
\hline $2.307,40$ & 26,09 & $2.286,50$ & 12,56 & 1,01 & 0,97 & $1.967,70$ & 23,32 & $2.046,30$ & 12,48 & 0,96 & 0,97 \\
\hline $2.291,30$ & 24,83 & $2.284,50$ & 12,57 & 1,00 & 0,93 & $1.955,10$ & 22,50 & $2.042,00$ & 11,95 & 0,96 & 0,98 \\
\hline $2.292,60$ & 25,46 & $2.282,90$ & 12,75 & 1,00 & 0,94 & $1.932,90$ & 21,87 & $2.038,90$ & 11,60 & 0,95 & 0,99 \\
\hline $2.301,80$ & 24,41 & $2.282,10$ & 11,76 & 1,01 & 0,97 & $1.816,50$ & 20,00 & $2.025,00$ & 11,91 & 0,90 & 0,93 \\
\hline $2.281,60$ & 25,94 & $2.278,80$ & 13,21 & 1,00 & 0,93 & $1.878,40$ & 21,31 & $2.011,30$ & 11,60 & 0,93 & 0,99 \\
\hline $2.234,30$ & 25,76 & $2.251,00$ & 12,78 & 0,99 & 0,97 & $1.825,40$ & 20,91 & $1.993,20$ & 11,51 & 0,92 & 1,00 \\
\hline $2.268,70$ & 24,33 & $2.250,60$ & 11,91 & 1,01 & 0,97 & $1.788,00$ & 21,64 & $1.935,90$ & 12,26 & 0,92 & 0,98 \\
\hline $2.279,70$ & 25,35 & $2.249,50$ & 12,87 & 1,01 & 0,93 & $1.252,30$ & 15,05 & $1.678,50$ & 11,02 & 0,75 & 0,98 \\
\hline $2.237,10$ & 24,73 & $2.249,30$ & 12,35 & 0,99 & 0,96 & $1.292,00$ & 15,25 & $1.650,80$ & 10,89 & 0,78 & 0,98 \\
\hline $2.245,70$ & 24,59 & $2.248,90$ & 12,66 & 1,00 & 0,93 & $1.018,80$ & 12,27 & $1.541,60$ & 10,36 & 0,66 & 1,00 \\
\hline
\end{tabular}

I 206/238: idades ${ }^{206} \mathrm{~Pb} / 238 \mathrm{U}$, em milhões de anos; I 207/235: idades ${ }^{207} \mathrm{~Pb} / 235 \mathrm{U}$, em milhões de anos; Conc.: concordância; *RHO: correlação de erro definida como o quociente da propagação de erros das razões ${ }^{206} \mathrm{~Pb} /{ }^{238} \mathrm{U}$ e ${ }^{207} \mathrm{~Pb} /{ }^{235} \mathrm{U}$. 